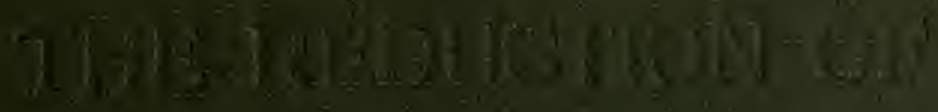
momast. Musauln.

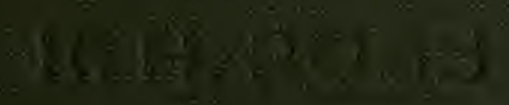




\section{PUBLIC HEALTH LIBRARY}

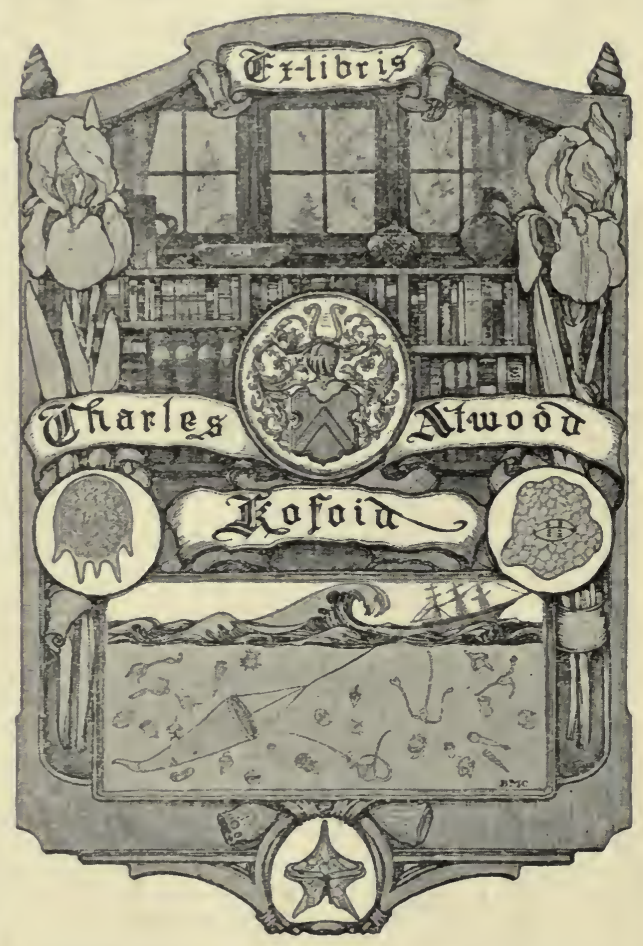




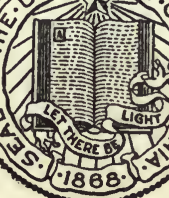

\section{THE LIBRARY} OF

\section{THE UNIVERSITY} OF CALIFORNIA

PRESENTED BY

PROF. CHARLES A. KOFOID AND

MRS. PRUDENCE W. KOFOID 


Digitized by the Internet Archive in 2007 with funding from Microsoft Corporation 


\section{THE REDUCTION OF DOMESTIC MOSQUITOS}






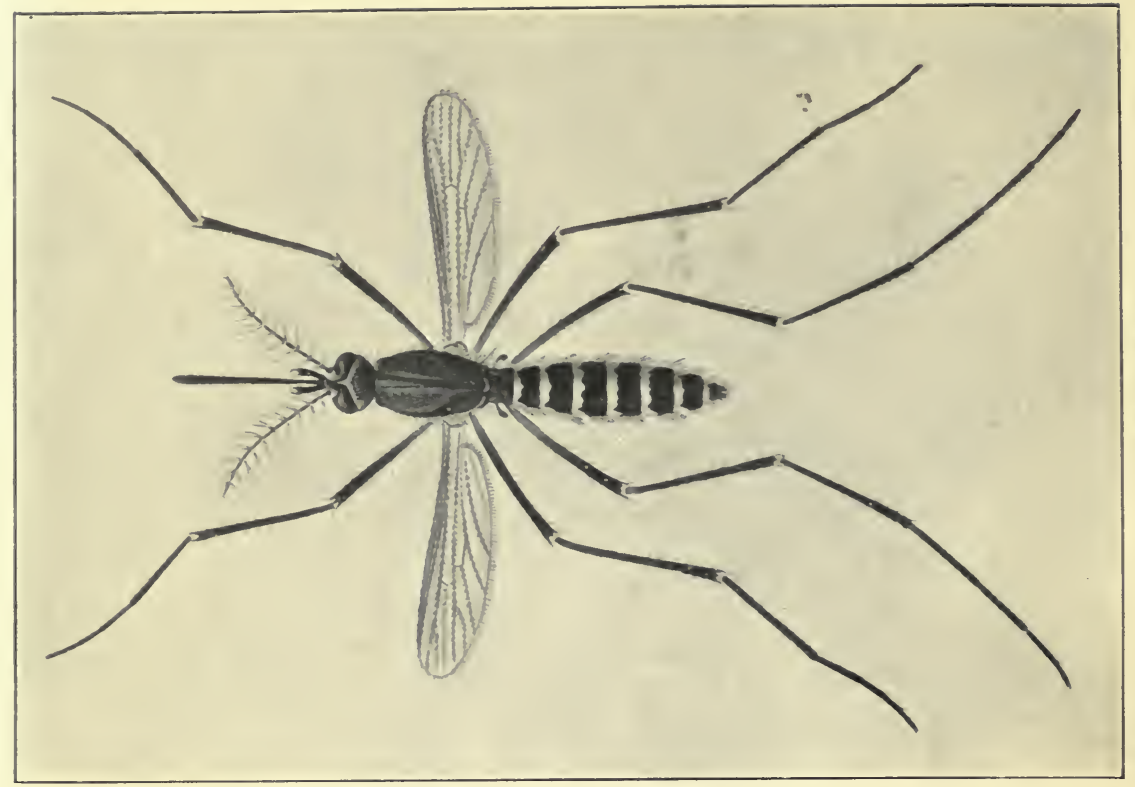

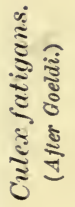

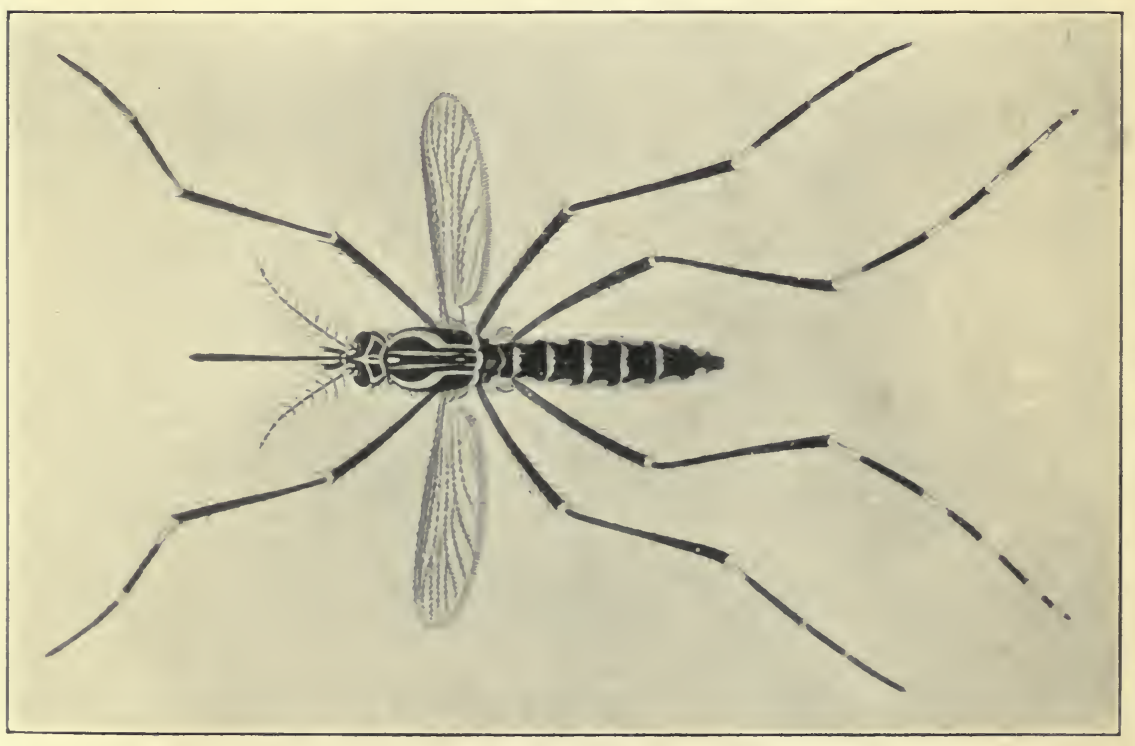

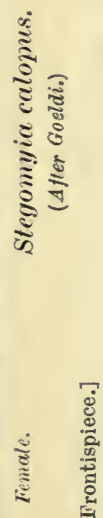




\section{THE REDUCTION OF DOMESTIC MOSQUITOS}

INSTRUCTIONS FOR THE USE OF MUNICIPALITIES, TOWN COUNCILS, HEALTH OFFICERS, SANITARY INSPECTORS, AND RESIDENTS IN WARM CLIMATES

\section{By EDWARD HALFORD ROSS \\ M.R.C.S. Euginad, L.R.C.P. Londoe Liverpool School of Tropica! Miedicine Lntw Health Ofiner. Pert Said and Suoz Camal Dintrict \\ Auther of \\ "The Prevention of Fovar on the Suez Caral"}

WITH ILLUSTRATIONS

LONDON

JOHN MURRAY; ALBEMARLE STREET, W. 


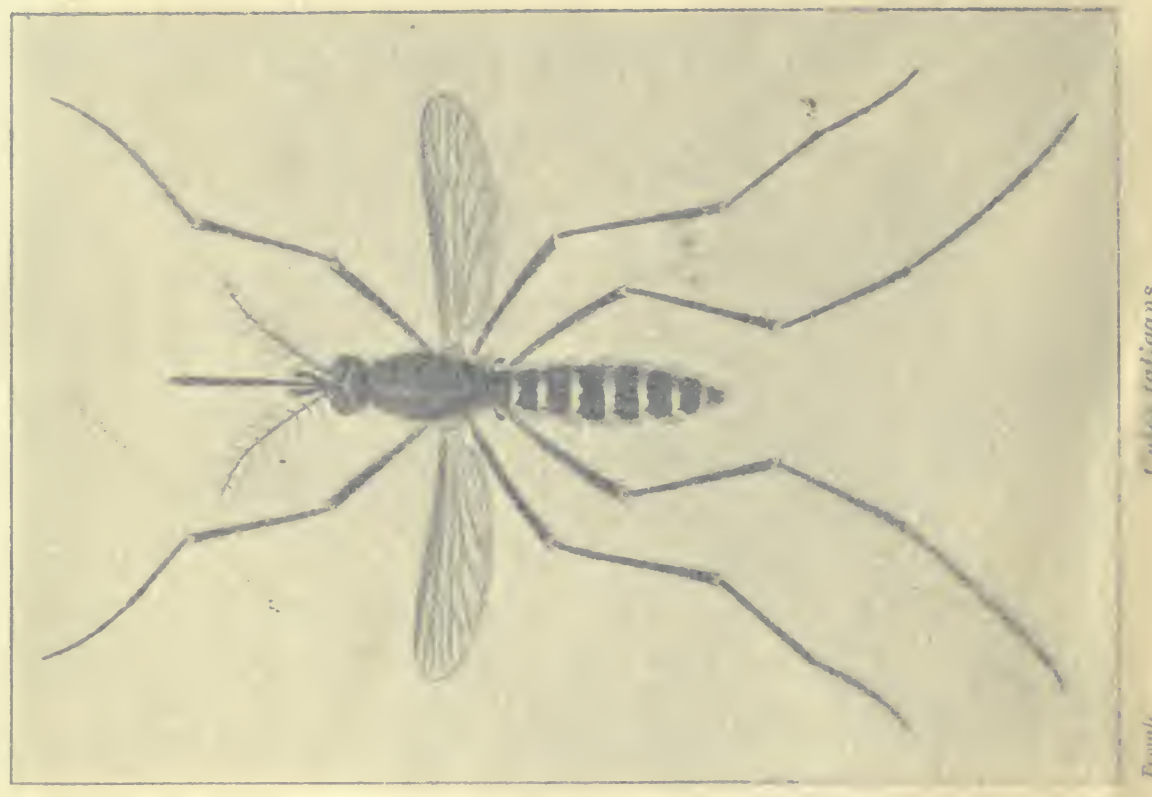

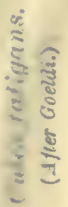

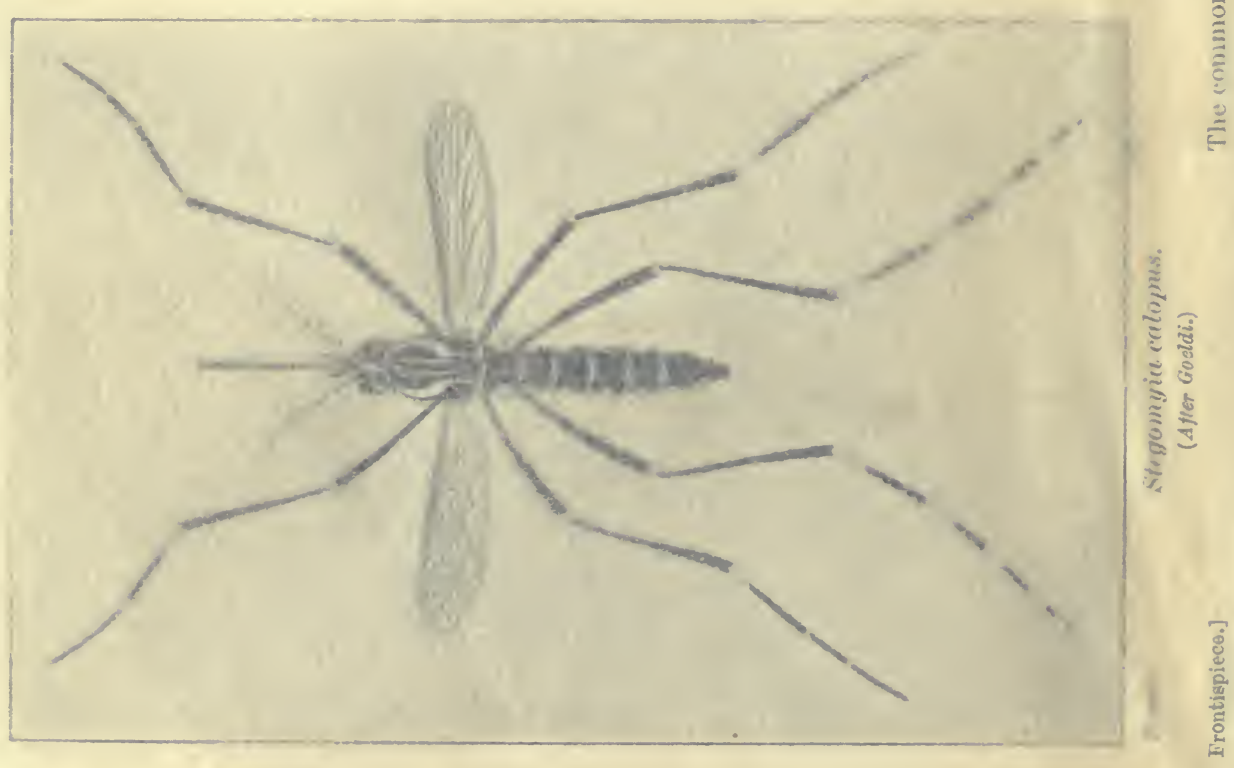




\section{THE REDUCTION OF DOMESTIC MOSQUITOS}

INSTRUCTIONS FOR THE USE OF MUNICIPALITIES, TOWN COUNCILS, HEALTH OFFICERS, SANITARY INSPECTORS, AND RESIDENTS IN WARM CLIMATES

\section{By EDWARD HALFORD ROSS}

M.R.C.S. Eagland, L.R.C.P. London

Liverpool School of Tropical Medicine Late Health Officer, Port Said and Suez Canal District

Author of

"The Prevention of Fever on the Suez Canal"

WITH ILLUSTRATIONS

LONDON

JOHN MURRAY, ALBEMARLE STREET, W. 




\section{GONTENTS}

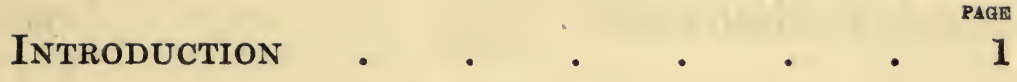

CHAPTER I

The Importance of Domestic Mosquitos . 16

CHAPTER II

The Life and Habits of Domestic Mosquitos 24

CHAPTER III

The Fever Census . . . . . 38

CHAPTER IV

Estimating the Cost of Mosquito ReducTION $\quad$. $4 \quad . \quad . \quad . \quad 48$

CHAPTER V

Ways and Means • • • • $\quad$ - 55

CHAPTER VI

Preliminaries . $\quad$ - $\quad$ - $\quad$. 61 
viii

CONTENTS

CHAPTER VII

The Start of the Mosquito Campaign

CHAPTER VIII

Progress . $\quad$. $\quad$.

CHAPTER IX

Mosquito Reduction • • • • • 88

CHAPTER $\mathrm{X}$

Reporting Progress . $\quad$ • $\quad$ - 96

CHAPTER XI

Finance . . . . . . . 104

CHAPTER XII

Results . . . . . . . . 110 


\section{LIST OF ILLUSTRATIONS}

1. The common domestic mosquitos: Stegomyia calopus and Culex fatigans (after Goeldi) . . . Frontispiece

FAOING PAGE

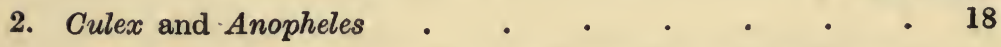

3. Larva of Stegomyia calopus. Breathing-tube of Culex larva 18

4. Eggs, egg-rafts, and pupæ of domestic mosquitos. The birth of the mosquito from the pupa (after Reaumur) - 26

5. The larval metamorphoses (after Blanchard) • • 26

6. Head of male Culex and head of male Anopheles (after Newstead) • • • • . . . . 33

7. Plan of breeding-places of domestic mosquitos at New Orleans (after Boyce) • . • . . . 51

8. Port Swettenham in the Federated Malay States. Now cleared of mosquitos, and healthy (after Watson) : 56

9. A house cistern. It is a breeding-place for domestic mosquitos (after Boyce) . . . . . .

10. A water-butt. A breeding-place for domestic mosquitos (after Boyce) • • • • • • • • • $\quad 71$

11. A borrow-pit in which domestic mosquitos breed - 85

12. A sewage-flooded backyard breeding domestic mosquitos. 85

13. Port Said on the Suez Canal, formerly very insanitary; now cleared of mosquitos and healthy. Each house in the town is visited by a mosquito brigade at the same hour of the same day every week . . . . 
PAOET PAGE

14. A favourite breeding-place for domestic mosquitos . $\quad 96$

15. A cesspool under a native hut will produce many mosquitos

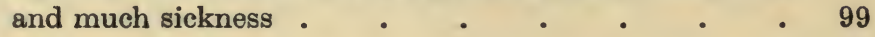

16. Native child with an enormously enlarged spleen from malaria . . . . . . .

17. The town of Ismailia on the Suez Canal, formerly very malarious; now cleared of mosquitos and healthy. Each house in the town is visited by a mosquito brigade at the same hour of the same day every week . 107

18. The town of Klang in the Federated Malay States, now free from mosquitos and healthy (after Watson) . . 111 


\section{The Reduction of Domestic Mosquitos}

\section{INTRODUCTION}

THE object of this book is to bring to public notice the necessity for the reduction of domestic mosquitos in towns and villages, and to describe how it is best accomplished. The experience that has been gained on the Suez Canal, where mosquito reduction has resulted in a great amelioration of the public health, is utilised as a basis.

The book is written at the suggestion of Professor Ronald Ross, who, after his discovery that malaria is transmitted by mosquitos, was the first to suggest municipal measures against those insects that infest towns as well as those more rural species that commonly carry malaria. In his book "Mosquito Brigades and How to Organise them," published in 1902, he drew attention to the importance of directing operations against all kinds of mosquitos, wherever communities of human beings are afflicted by them; and he proposed and advised the formation of brigades to fight the domestic species as well as the malaria-carrying ones. 
The towns of the Suez Canal have been cleared of all kinds of mosquitos. At Port Said, the commonest species found before work was started were Culex fatigans and Stegomyia calopus. These are perhaps the common varieties of domestic mosquitos, and it is these which will be specially considered in this book. In most towns and villages in warm climates domestic mosquitos abound; but when such towns are not also afflicted with the malaria-conveying Anophelines, it is often thought not worth the necessary expenditure to institute a municipal campaign against the others. The experience gained at Port Said shows that this is a fallacy. It is most important, and indeed absolutely necessary, to reduce and to abolish, if possible, the mosquitos that breed in and near houses in towns as well as the more rural sylvan species that carry malaria.

The following pages, therefore, deal entirely with the reduction of the genera Culex and Stegomyia; but measures against them will also be efficacious in ridding the town of Anophelines which happen to be breeding within its precincts. This was found to be the case at Port Said-though the campaign there was originally started against the domestic species only; the presence of Anophelines in that town was discovered afterwards.

By the ancient historians domestic mosquitos were considered a great pest ; for mosquito nets were used by the Romans and Ancient Greeks. Professor Ross, in his book "The Prevention of Malaria," writes : 
"Mr. Robert Gladstone and Mr. Jones have kindly called my attention to several passages referring to mosquito nets, called conopeum by the Romans, after the Greeks (our word canopy). Herodotus first noted with surprise the use of them in Egypt; and they are referred to later in Varro ('De Re Rustica'), Horace ('Epodes'), Propertius, Juvenal, and Paulus Silentiarius ('Anthologa Palatina'). Horace says, "And among the military standards, oh, shame! the sun sees a mosquito curtain'; and Propertius calls these nets foda (foul or disgraceful). Evidently, the ancients felt towards them as do many of our own more manly colonists, who prefer annoyance, and even sickness, to disgrace. But Paulus Silentiarius thought that they were useful for a postprandial siesta in order to save the slaves the trouble of using a fly-flapper. Varro said that women lately confined spent a number of days in them; and Juvenal said that they were used to cover the cradles of the rich and noble."

If these writers could visit Egypt now, they would still find the mosquito nets in most towns; though at Ismailia and Port Said this "disgrace" has at last, after all these years, been removed. The fact, recognised by Juvenal, that the poor cannot afford mosquito curtains, explains the greater incidence of fevers among children living in the poverty-stricken quarters of tropical towns.

It seems probable that the Ancient Greeks, even in the time of Hippocrates (about 460 B.c.), associated marshes with fevers, though the connection of the 
homely urban mosquito with disease was not realised. The text-book already quoted states that Empedocles of Agrigentum is said to have drained a marsh, and made Selinus in Sicily healthy about 550 years B.C. Strabo (first century B.c.) remarks that Alexandria was free from marsh fever in his time (Alexandria now is surrounded by very salt sea-water marshes in which malaria-carrying mosquitos do not breed). I have mentioned elsewhere the possibility that marsh and mosquito-carried disease may have accounted partly for the downfall of the ancient empires of Egypt and Mesopotamia, caused by the over-irrigation and want of drainage in those river-dependent countries; the land of the delta of the Nile is now becoming waterlogged, owing to deficient drainage and excessive irrigation under the present-day civilisation. Professor Ross and Mr. Jones have already suggested, and collected considerable evidence to prove, that malaria assisted in the decadence of Greece. The Cretans, Greeks, and Romans had some wonderful agricultural drainage arrangements, remains of which may be still seen in some places; and there is a remarkable old masonry drain under the city of Beyrout, which must have existed for centuries. Ancient civilisations probably realised the danger of marshes, swamps, and even urban stagnant water-collections, but their remedies were never very successful, because the actual cause of the danger-mosquitos-was not understood, and was not revealed until the end of the nineteenth century.

According to Mr. P. V. Theobald, the author of 
the exhaustive monograph on mosquitos which was written at the instance of Sir E. Ray Lankester, formerly Director of the British (Natural History) Museum, the earliest attempts at a classification of

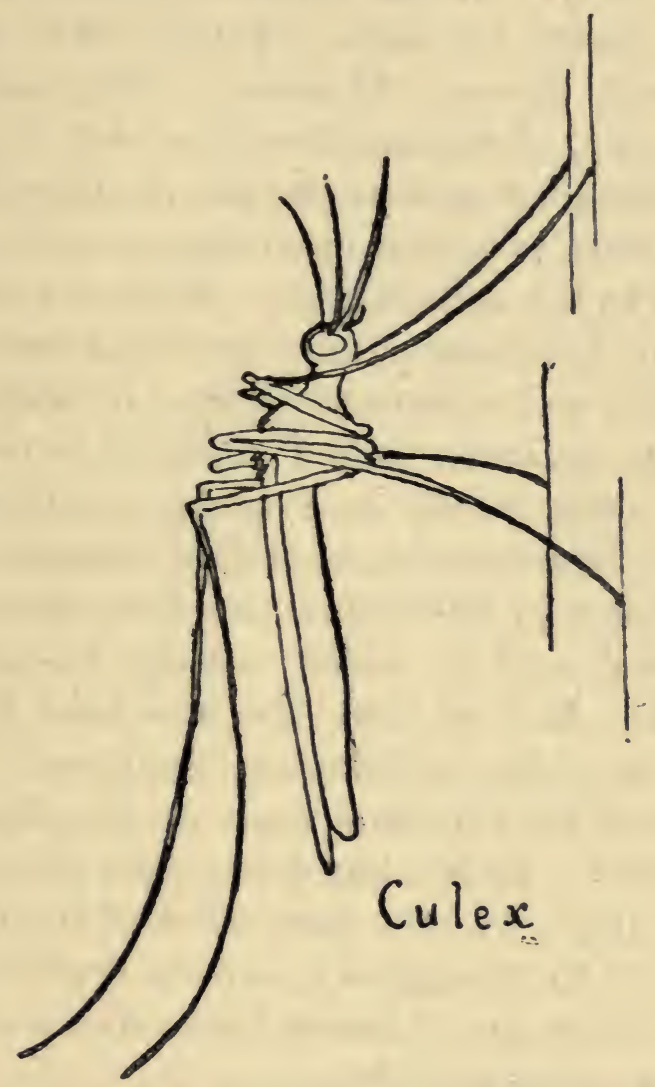

these insects (which belong to the Diptera, and to the family Culicidæ) was made by the naturalist Linnæus in 1735, who described the genus Culex (which contains the common domestic species), and upon this genus, with its type Culex pipiens, the family 
characters are founded. Fabricius in 1805 first designated the " tiger" mosquito, Stegomyia fasciata, although Villiers had probably described the same insect before; Meigen called it Stegomyia calopus, very soon after. In 1825 Latreille grouped mosquitos generally under the name Culicidæ, but only three genera were known, Anopheles, Culex, and Ades. Subsequently, Robineau-Desvoidy and Arribalzaga added several new genera, but the classifications were very confused, several names being given by different observers to the same species. Even the name mosquito itself has many synonyms; it is derived from the Spanish, and means a small fly. In England these insects are variously called gnats or mosquitos, in German, stechmüchen, in French, moustiques (mosquito net, moustiquaire), in Italian, zanzari, in Spanish, mosquitos, in Hindustani, muchers (mosquito net, mucher-jala), and in Arabic, nemoos (mosquito net, nemoosieh). But in $1901 \mathrm{Mr}$. Theobald began the publication of his well-known monograph, and this has become the standard work on the classification of the insect. As he himself explains, the reason for the monograph was the discoveries of the important part played by mosquitos in certain diseases. These discoveries are now common knowledge, and need be but shortly mentioned here.

According to Nuttall, it was in 1878 that Bancroft and Cobbold first suggested that the human bloodworm, Filaria bancrofti, might be carried by mosquitos. This suggestion was based on the knowledge obtaining then that certain Nematode and Cestode 
worms, parasitic in certain animals, passed portions of their life-cycles within the bodies of certain other animals or insects, now called intermediate hosts. At the same time Manson came to the same conclu-

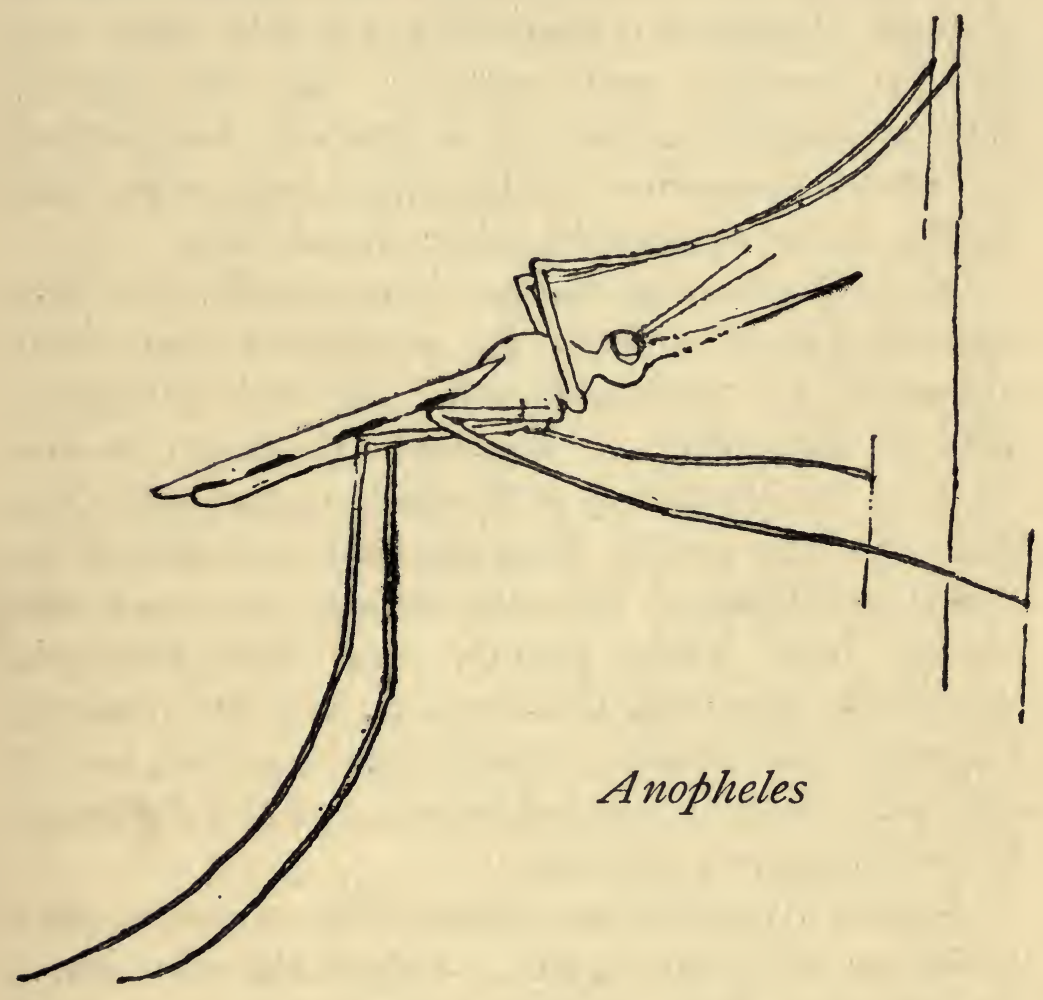

sion when in China, and he made his now famous discovery that the embryos of Filaria bancrofti develop in the tissues of mosquitos which had fed on infected Chinamen, and which had been caught in their houses. However, the final transfer of the nearly developed embryo worm from the mosquito to 
man has never been practically demonstrated, though there is strong presumptive evidence in its favour.

Then followed the well-known discovery by Ronald Ross, published by him in 1897-9 : first, that the domestic grey gnat conveys the malaria parasite of birds (Proteosoma danilerwski of Labbé) from one bird to another, and secondly, that the human malaria parasite of Laveran is similarly transmitted by certain mosquitos of the dapple-wing type that belong to the sub-family called Anopheline.

As in the case of filariasis, the possibility of the transmission of malaria by mosquitos had been suggested by many observers; but this discovery differed from that of Manson's, inasmuch as the whole of the life-history of the malaria parasite in the mosquito was clearly demonstrated and proved by actual experiment. Its confirmation was soon forthcoming from Koch, Daniels, and from Bignami, Bastianelli, Stephens, Christophers, and many others. Practical transmission experiments in human beings were performed by many observers, and this discovery is now absolutely proved.

Serious attention was consequently drawn to mosquitos as dangerous pests. Immediately following his discovery, Ross, in 1899, suggested to the Indian Government the possibility of reducing mosquitos in a malarious district, basing his proposals on observations and experiments conducted during the previous years in India. These experiments showed that mosquitos in a house could be reduced by the simple procedure of periodically emptying out the rain-water 
collected in tubs and pots in the garden. On his retirement from the Indian Service, the matter was taken up by the Liverpool School of Tropical Medicine, which had just been established, and expeditions to West Africa were organised. This was the beginning of a movement which has resulted in the clearing of many unhealthy spots and districts in warm climates. Reduction of domestic mosquitos is a branch of this movement.

The discovery of the transmission of malaria by mosquitos was rapidly succeeded by that of the transmission of yellow fever in a similar manner. At the end of last century, Reed, Carrol, Lazear, and Agramonte, working in Cuba, found that the ultramicroscopic virus of yellow fever is conveyed from one human being to another by the domestic species of mosquito, Stegomyia calopus. This was followed by the work of Graham of Beyrout, and of Ashburn and Craig in the Philippines, which showed that the similar virus of dengue fever is conveyed by the domestic mosquito that is so common, Culex fatigans.

In the meantime, measures against malaria and yellow fever had been started in many places. For a full description of these, "The Prevention of Malaria" quoted above, and "Mosquito or Man," by Sir Rubert Boyce (London, Murray), should be consulted; there is only space to mention shortly some of these campaigns here.

The first suggestion, that the best way to extirpate mosquito-borne disease is to reduce the number of breeding-places of the insects, was made in the letter 
to the Government of India before mentioned, dated February 16, 1899. This suggestion was published in The Indian Medical Gazette, and in The British Medical Journal for July 1899; and a few months later Professor Ross made similar proposals in detail for Sierra Leone. As a result, a limited campaign l against Anophelines was begun at Hong-Kong in $\mathbf{1 9 0 0}$ by Young and Thomson, and the results published by them in The British Medical Journal, September 16, 1901. So far as it went, this limited campaign was successful, and it holds the honour of being the first. Then Dr. Doty instituted, early in 1900, measures for the reduction of all mosquitos in Staten Island, near New York. But the first extensive campaign was that started at Havana in the spring of 1900 against all kinds of mosquitos. Havana is a city of 250,000 people, and it remains famous for continuing one of the largest and most complete sanitary campaigns ever organised; yellow fever has been abolished. Two months after Havana, Professor Ross followed suit by organising a campaign against both AnopheI lines and Culecines in Sierra Leone, Bathurst, and other towns of the Gold Goast that were infected with malaria. Simultaneously, Sir William MacGregor, G.C.M.G., and Dr. Strachan at Lagos tried the effects of window-screening and the distribution of quinine and the drainage of marshes against that disease. These were the earliest campaigns.

The clearing of Ismailia in 1902, at Professor Ross's advice, was the next undertaking. The town was racked with malaria. Both Anophelines and 
Culecines were abolished, with the result that malaria and all other fevers have disappeared, except for an occasional case of typhoid. Now mosquito nets are not necessary at Ismailia. Then, in 1905, at New Orleans, measures against yellow fever were adopted, and Stegomyia and all domestic species dealt with during an epidemic of that disease; this campaign has been fully reported by Sir Rubert Boyce. But before this, Colonel Gorgas and Dr. Malcolm Watson began their famous sanitary campaigns against all species of mosquitos in the Panama Canal I Zone, and at Klang and Port Swettenham respectively; the former is reported in The Times, by Sir Harry Johnstone, April 17, 1909, and by Dr. Osler in The Lancet of October 26, 1909, and the latter in Dr. Watson's book "The Prevention of Malaria in Ithe Federated Malay States." The city of Rio de Janeiro was made healthy by freeing it from malaria and yellow fever-the annual sanitary budget increasing from $£ 40,000$ to $£ 680,000$; Santos in Brazil has been dealt with similarly (de Cruz, The Times, December 28, 1909). In addition to these, successful campaigns have been carried on against either one or both of these diseases at the following places: British and Spanish Honduras, in the Philippines, Jamaica, Antigua, Mauritius, and in Southern Nigeria. In Italy, Greece, and in Algeria mosquito reduction is being conducted in various places. Even India, where the original discovery which has led to these great sanitary reforms was made, is now, after ten years' thought, more seriously considering the 
adoption of measures carried out so successfully in other countries. Egypt, with the exception of the Suez Canal Zone, is still backward, and the Khedive's Government continues to regard mosquito reduction as a fraudulent fetish. That country is under some spell. Its tombs, its mummies, its Pyramids, its " honourable dead," appear to be more important to it than the health of the living. The Sphinx continues to gaze over Cairo with its death-rate of 40 per 1,000 .

But these mosquito campaigns have always been instituted on account of either malaria or yellow fever. There is, consequently, an impression, even among medical men, that unless malaria or yellow fever actually exists in a community there is no necessity to try to reduce mosquitos. Persons who have been for a long time resident in warm climates may become immune to mosquito bites, and do not feel them, and if they themselves are seldom sick from malaria, or never have yellow-jack, they are inclined to laugh at the suggestion of an anti-mosquito campaign. They say: "There are no Anophelines here, nor is there any yellow fever. Why bother about Culex or Stegomyia, then ? These mosquitos do no harm."

The Culecine or domestic mosquito does no harm. Dengue fever is carried by the domestic and ubiquitous Culex fatigans. Yellow fever is transmitted by Stegomyia calopus, the common speckled gnat. And if these fevers do not exist in the town there is always the possibility of their introduction in these days of rapid travel and communication. But is it certain 
that these diseases do not exist in a mild form among the native children, and may not break out in an epidemic ? The same applies to malaria as well as to yellow and dengue fevers. Is it certain that the town is quite free from such disease ?

In addition to this danger, which is surely important enough, the domestic mosquitos are disgusting insects that pass their larval lives in cesspools, blocked-up canal-ends, water-butts, and even in the seal water of drains and such-like collections of filthy water; and the newly hatched flying insects feed on the floating matter found in such water. Then they proceed to suck the blood of the first human being they can find, thrusting their infected proboscides through his skin. The existence of domestic mosquitos in a town or village should be regarded as a sign of insanitation, and their numbers as a measure of that insanitation.

Mosquitos are a terrible pest. It is difficult for people at home to realise what a worry they are. While one is working or reading in the evening or trying to write in one's office in the daytime, the Culex or the Stegomyia is biting one's ankles or wrists. Work must be stopped while searching for a fly-flapper or a weapon of some sort. Then ensues a hunt in which the mosquito generally has the best of it. Settle down to read again. "Ping" behind the ear. Fly-flapper again. Then the same hunt-no rest, no peace. It is bang, flap, scratch, rub, itch, rub again, complaining incessantly. All work ends. The only restful place is in the mosquito curtain; but how hot 
and unhealthy it is! The air inside does not stir. If there is any wind the mosquito net will keep it out. It is too hot to tolerate bed clothes inside this muslin bag. Then if a hand or foot touches the net during sleep, a mosquito will wreak her vengeance by thrusting her proboscis through the mesh, and then the disturbed sleep and the constant itching and scratching. These things must be endured to be realised. Think of the number of people who cannot afford even a mosquito curtain. Think of the children. How much better to get rid of mosquitos entirely, and live in comfort!

The reduction of the domestic species of mosquitos presents no difficulties. Given the necessary means, it requires only organisation and perseverance. It should be regarded as a measure of economic importance, for it improves the public health. In all towns where mosquitos exist the local authority should be forced to undertake their reduction as a routine measure, and it should not be left to private enterprise. The cost of the mosquito campaign should be included in the municipal budget as a very desirable reform.

Mosquito prevention in towns has certain definite results, if properly carried out.

1. It prevents certain diseases.

2. It is a popular measure.

3. It necessitates a regular weekly examination of houses, yards, latrines, ashpits, water-closets, cesspools, and all insanitary places by the sanitary authority; and if the public believes that this 
examination is being carried out in order to prevent mosquitos there will be no opposition.

4. It interests the inhabitants, and encourages them to notify sickness and the return of mosquitos to the local authority.

The cost is not great. It varies, of course, in different countries, for it is dependent upon several variables, such as the cost of labour, petroleum, etc. But a municipal rate of sixpence per head of population per year in large towns will generally cover the cost of the upkeep of a mosquito campaign, though this rate may be increased owing to a heavy summer rainfall, much exposed infiltration water, irrigated gardens or parks, and decreased by a complete system of sewerage with good and constant pressure on the town water-mains, and other factors.

But if a mosquito campaign is persevered with its cost will gradually diminish, as it has done at Port Said. Then the organisation may be utilised for further sanitary work. It will be a trained organisation, and can be taught to report on the presence of diseases other than those conveyed by mosquitos; it can be made to examine unhealthy shops and overcrowded factories, for example. But the original idea must never be lost sight of. If the mosquito work is neglected for a single week, the insects will surely return, and then the work will fall into disrepute. Perseverance and constant attention and supervision are necessary for success; but these, with the money expended, will be amply repaid by the improved health and comfort of every one. 


\section{CHAPTER I}

THE IMPORTANCE OF DOMESTIC MOSQUITOS

As described in the Introduction, it was the discovery that malaria is conveyed by mosquitos which first seriously directed attention to the different varieties of that insect. For years, in India, Ross had attempted to transmit intermittent fever by the common grey gnat and by the speckled gnat; but the attempts were unsuccessful. Then came the discovery that malaria is conveyed from one human being to another by the dapple-wing mosquito, or Anopheline. This led to the classification of these insects. Mr. Theobald's classification is decided largely by the shape and form of the microscopic scales which cover the bodies and the veins of the wings of gnats, and also by the anatomy of their proboscides, etc. In this way mosquitos have been separated into a number of subfamilies, genera, and species. This is the scientific classification.

But there is another classification that is simpler than this : it is based on the habits of the different species. The type of mosquito that inhabits houses in towns or compactly built villages is different from the type that lives in marshes, forests, and on the 
banks of rivers. The species that lay their eggs on the surface of water contained in cesspools, in the dirty water in tubs, bottles in yards, in gutters, choked eaves, rainpipes, broken drains, in exposed collections of sewage, cisterns, flower-vases, or waterpots, are different from those that oviposit in shallow marshes, on the estuaries of rivers, in streams that flow slowly through woods, in the water that collects stagnant at the end of irrigation channels, or in ponds in the jungle. In some places, of course, both kinds of mosquito are found together. For example, in the houses of villages on the borders of swamps, or near ricefields or flooded meadows, and in towns where there is much irrigation, many gardens, or public parks, the species of mosquito found may belong to both the domestic and sylvan families; but in the larger towns and villages the domestic species are always the commoner even if the others exist. This is because mosquitos will not fly far from their breeding-places unless there happens to be no food for them near : the marsh-gnat will remain near the marsh, the house-gnat will not go far from the backyard. Therefore it may be said that the kind of mosquito found commonly in towns belongs, for the most part, to the subfamily called Culecine; the Culecina are subdivided again into many genera, the commonest of which are the Culex and Stegomyia; and these again into many species. It is these which are dealt with here; other works must be consulted if the malaria-carrying Anopheline is very common in the town. But for 


\section{THE IMPORTANCE OF DOMESTIC MOSQUITOS}

the sake of those who are not familiar with the different characters of the insects, it may be as well to describe the different appearances. The Culex stands on the wall or mosquito net with its body parallel to the surface; the Anopheles holds its body straight out almost perpendicular to the wall. The Culex rarely has marked wings; the Anopheles nearly always has spotted wings. The female Culex has short palpæ; the female Anopheles has long palpæ. The two insects have so often been pictured together, and their difference is so well known, that their discrimination is an easy matter. All medical men know the Anopheline from the Culecine.

The Culecine mosquito has many varieties or species, but for practical purposes these may be collected into two groups-the common grey gnat and the speckled gnat. These two forms are generally found together, in warm climates, in towns, villages, standing camps, and on board ships-in fact, in all communities of human beings. The grey gnat is a sombre, grey or brown, or even a black mosquito which haunts rooms in the evening or at night. In the early morning it can always be seen resting on the mosquito curtain tired and well fed after its nocturnal labours. It likes to have a final feed just before dawn. The speckled Stegomyia is the brightly coloured, black-and-white striped mosquito which bites in the daytime, especially just after the dawn. It haunts dark clothes and shady verandas. These are the two common domestic mosquitos. 

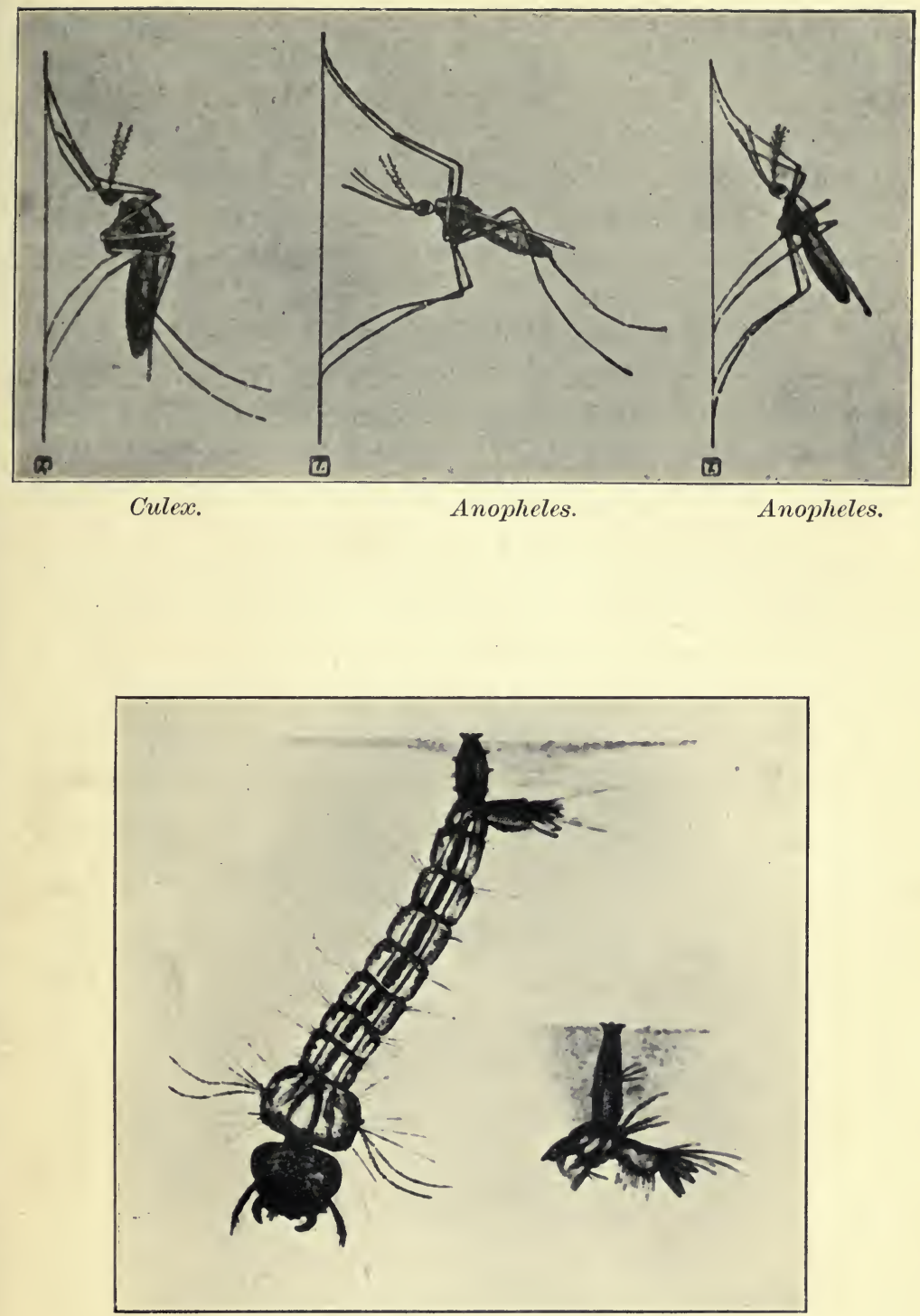

Larva of Stegomyia calopus.

Inset: breathing-tube of Culex larva.

p. 18] 

The former of the two species conveys dengue fever and the latter yellow fever; both, therefore, are dangerous pests. It may be argued that there is no dengue nor yellow fever in the town, and therefore there is no need, nor is it justifiable, to spend public money in preventing these mosquitos. But is it certain that these two diseases do not exist in the locality?

The doctors should be interrogated. It is probable that there is fever prevailing in the summer. The children may be suffering from slight fever in the hot weather. Information on this point can be obtained from the schools. It may be called sun fever, or influenza. Perhaps a factory has been closed in the hot season because the men are sick. If inquiries are made it will be found that few towns in warm climates can claim an absolutely clean bill of health all the year round. Port Said, five years ago, before the mosquito campaign was started, was said to be free from malaria. But the town was admitted to be unhealthy; its name was a byword. And then, on inquiry, it was found that, every summer, people-men, women and children, European and native-used to contract fever. In reality there was fever of short duration-four, five, ten days' fever, followed by weakness and lassitude. Children were frequently ill. A mother would say that the baby was tired and fatigué ; she was obliged to keep it in bed for twelve days in a stuffy bedroom. Then such schools as existed in those days were frequently empty in the hot weather. The men in 


\section{THE IMPORTANCE OF DOMESTIC MOSQUITOS}

an engineering workshop would suddenly have to stop work ; the manager would growl, saying that it was no good going on with his men sick: "I have discharged one gang and have engaged another; but now they are sick too."

This was "culex fever." Repeated attacks of it rendered people pale and lifeless. The children were stunted, anæmic, and unhealthy-looking. Men were frequently out of work for days on this account, and after several attacks their employers discharged them. The men, being unemployed, wandered about the quays and annoyed the passengersthey were forced to get a livelihood somehow. This was the cause of Port Said's name. In these days sick men are no use to any one anywhere.

Then, what a pest mosquitos used to be at Port Said! Every one complained about them. We were annoyed all day as well as all night. Even in the winter the Culecines were a nuisance. Stegomyia calopus hibernates in the cold, but Culex fatigans is very troublesome. The clerks in some of the offices were obliged to work under mosquito curtains, suspending them from the gas brackets over their desks. Native workmen in laundries covered their naked ankles with paper to keep off mosquitos. Passengers in the ships suffered too. The hotels and residential houses and flats were rendered intolerable in the evenings. Mosquitos followed one out on to the verandas and even in the streets. After a sleepless night one was pestered all day. The cause of it all lay in the insanitary condition of the town. 
The cesspools were old and leaky, and in many houses had burst into the cellars, and there the mosquitos were breeding in myriads.

New-comers felt the effects of mosquitos most. They were inexperienced in the use of mosquito nets. They forgot to tuck them in under their beds. They were bitten terribly. Their faces would sometimes be covered with the marks produced by the insects. Children especially suffered. The old resident was inclined to mock the new-comer, but he was bitten too, although he did not feel the bites so much; he was used to them. Only the mosquitos themselves were really happy.

Mosquitos were abolished, and that was the end of the trouble. Malaria had been already abolished at the neighbouring town of Ismailia, and we followed suit at Port Said. All kinds of mosquitos were dealt with as at Ismailia, and the town is now free from fever carried by these insects. It has made a great difference to life there. In the course of the mosquito campaign several interesting facts were brought to light. Malaria was found; the cause was Anopheles maculipennis and Cellia pharoensis-both species were found breeding in dirty. water. The most insanitary places were discovered and dealt with. The presence of a few Phlebotomus flies and an occasional case of three-day fever, which is conveyed by them, were noted. These small bloodsucking flies breed in stone walls, their eggs and larvæ being found in tiny crannies in the stone. The culex fever disappeared; so did the dengue; 
so did filariasis among the natives. The house-tohouse weekly visit of the mosquito brigades is now a regular institution, and it has been the means of accomplishing many sanitary reforms under difficult political conditions. But this work could never have been successful if the Anophelines had been attacked alone. It was the reduction of the domestic mosquito which pleased the people and which enabled the weekly examination of the town and the regular inspection of the dirty native quarter to be undertaken. There are no real sanitary laws in Egypt, and every man was master in his own house, and could build or repair or not as he liked; we could not force him to do anything, or even enter his house or premises without his permission. It was for the purpose of reducing their domestic mosquitos that the polyglot people of Port Said gave us their permission to enter their houses; but when the men did get in to the backyards and cellars they were able to do a great deal. As soon as the householder saw that we seriously intended to reduce his domestic mosquitos he no longer opposed, he actually assisted.

It is necessary therefore to reduce the Culecine mosquito as well as the Anopheline. Deal with the domestic mosquito whether the Anopheline is present or not in the town. It is a sanitary measure which it is the duty of citizens to perform. It is the prime function of municipalities and town councils to undertake sanitary reforms and to see that they succeed. Health is more important than a beautiful 
town; it is a greater lasting benefit than a statue to a great man. What is the use of an esplanade, a public garden, or a monument if people are too ill to use or to see them? 


\section{CHAPTER II}

THE LIFE AND HABITS OF DOMESTIC MOSQUITOS

BEFORE attempting to exterminate an animal or an insect, something must be known of its habits and ways. During the past few years much has been learned concerning mosquitos; but there still remains much that is not known.

It is only the female mosquito which sucks blood. This statement has been called in question, but in all probability it is correct. The male mosquito has a proboscis that is hardly framed for the purpose of piercing the skin. Certain authorities have claimed that they have seen a male mosquito of one or two species sucking blood like the female insect; but if such a thing does occur, it must be very rare. Of the great number of mosquitos examined and dissected by the author, on no occasion was a male found that had blood in its stomach. The mosquito differs in this respect from the flea. Both the male and female fleas live on blood. But with mosquitos, blood is not the only food. Both sexes will thrust their proboscides into various substances; and so far as the domestic species are concerned, the filthier that substance is, the more it is enjoyed. But the fecundated female seems to require blood for the 
maturation of her ova. Under natural conditions it must be very rare for virgin females to suck blood. As soon as the female mosquito has mated with the male she develops a sudden craving for animal blood. The hæmatophagus habit appears to be dependent on the presence, in the female, of the spermatozoa of the male. This statement also has been called in question. But of all the mosquitos dissected, among those actually caught in the habitations of human beings, which contained blood in their stomachs, not one was found that did not have living spermatozoa inside her spermathecæ. From this it must be inferred that virgin females do not, commonly, take blood; in captivity, perhaps, if they are starving the unfertilised female may be induced to pierce the skin with her proboscis. It is interesting to try to conjecture the nature of the changes, within the female, caused by mating with the male, which induces such an alteration in her dietary. In several small animals and insects-for. example, tadpoles and caterpillars - food is an important factor in the determination of sex. The well-known case of the honey-bee may be quoted. Here sex is determined by fertilisation, the males originating from unfecundated eggs by parthenogenesis, while the fertilised eggs produce the females. Then the food of the larva determines whether these females become barren workers or the queen bees. In the mosquito, however, the sexual factor determines the choice of the food-Nature appears to have reversed her procedure. 
The female mosquito lays her eggs in broods. After mating and after some meals of blood the female returns to water to oviposit. The domestic mosquito prefers dirty water on which to lay her eggs. She lays them either in rafts of three hundred at a time, or more loosely bound together; Culex fatigans affects the former, while Stegomyia prefers the latter. Anophelines lay their eggs singly. But the water collection must be sheltered from the wind, for the operation of laying three hundred or more eggs requires some time, and mosquitos cannot withstand a gust of wind-their wings and legs are delicate structures. The egg-raft of the Culex is about an eighth of an inch in length, and can be readily seen floating on the surface of the water. The eggs of Stegomyia merely cling together, and, although they can be seen by the naked eye, a magnifying glass is needed to distinguish the details of their form. The easiest way to find mosquito eggs in a warm climate is to leave a bucket of dirty water in the kitchen for a night, when the eggs will be found floating either in rafts or in batches on the water in the morning. They can then be gently lifted off the water, and examined under the microscope.

The domestic mosquito likes to lay her eggs on the surface of dirty water, for she knows that this will supply plenty of food for her children, the larvæ, when they have hatched from the eggs into swimming " wrigglers." This can be demonstrated by an interesting experiment. Place two buckets side by side in a 


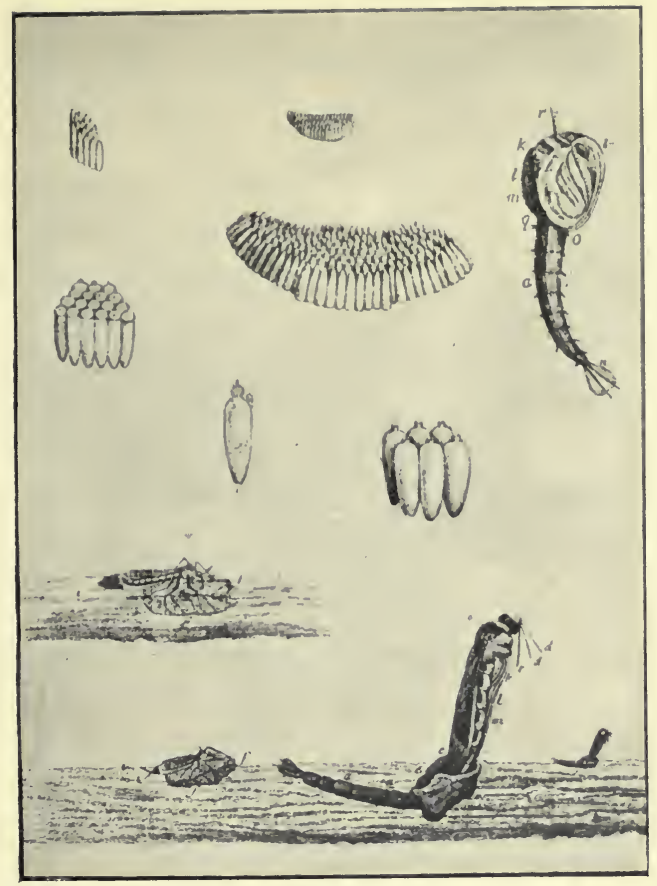

Eggs, egg-rafts, and pupa of domestic mosquitos. The birth of the mosquito from the pupa.

(After Reaumur.)

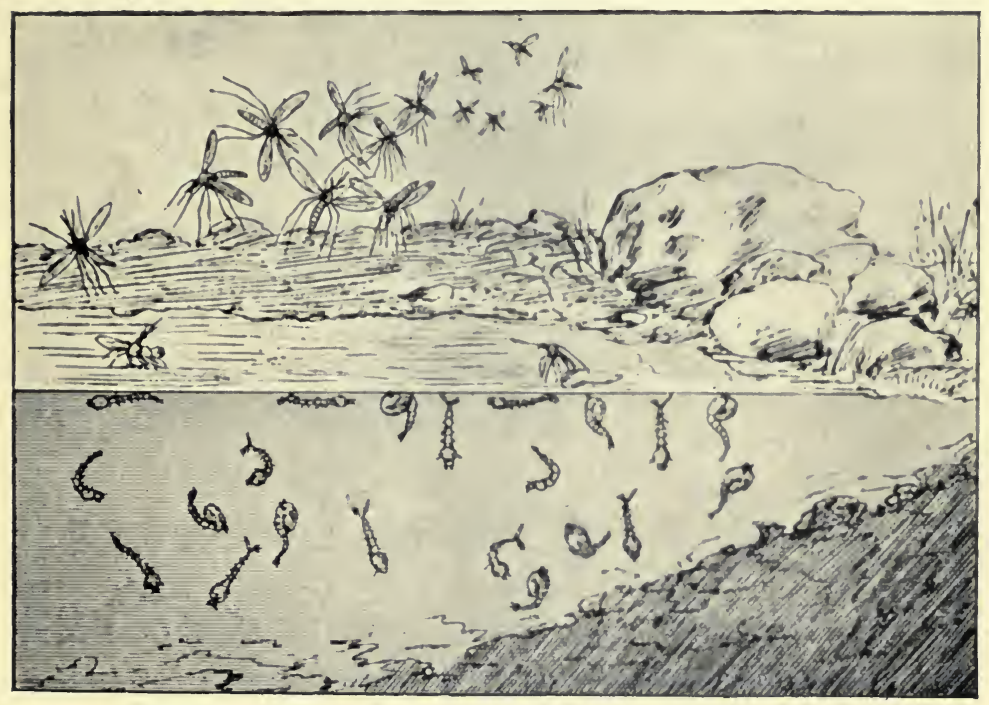

The larval metamorphoses, 

dark, quiet corner of a mosquito-infested house. Into one put some clean, filtered water, and into the other put an equal quantity of dirty water in which, say, the cook has washed the plates. Leave the buckets for three days, and if the water in them is then examined, numbers of mosquito eggs-batches and rafts-will be found floating on the surface of the dirty water, and few or none on the surface of the clean water. The maternal instinct drives the female mosquito of the domestic species to lay her eggs where her larvæ will thrive.

Each separate egg gives rise to one mosquito larva or wriggler. Each egg-raft or batch produces, therefore, a brood of swimming larvæ. These small aquatic insects are well known even in England during the summer. If after a heat-wave the water-butt in the garden is examined, hundreds of these fish-like insects can usually be seen in the water. They are worth watching. Note how they avoid the direct sunlight, and keep to the shady edges of the tub. Here they collect, their heads hanging downwards, their tails touching the surface of the water. When disturbed, they wriggle down to the bottom of the water. They feed on such minute, living or dead, animal or vegetable particles as they can find.

The Culex larva differs slightly from the Stegomyia; the former, when resting near the surface of the water, is nearly perpendicular to it, the latter is at an acute angle to the surface. The Culex larva possesses a long tube in its tail through which it 
breathes the air, the Stegomyia has only a short tube. The mosquito larva spends at least ten days in the water before it emerges into the air as a full-grown mosquito. During this time it grows much larger, and undergoes four moults. For the last twenty-four hours prior to its birth into the world as a flying insect, it is found in the comma-like stage known as the pupa or nymph. During this stage it bobs about in the water, breathing at the surface, but takes no food. All these stages are known as the larval metamorphosis.

From the moment the mosquito egg is laid, the living larva begins its battle of life. Its life in the egg itself is very short if there happen to be any goldfish in the water, or a bird may gobble up the whole egg-raft. As soon as the larva has left the egg and become a swimming wriggler, its first trouble may be to find food. Its mother has flown away to annoy another human being or animal, and has left it to take care of itself, together with its three hundred brothers and sisters. If the mosquito larva can find suitable food, and the water is warm, it grows rapidly, moulting its skin every two or three days, and gradually growing darker in colour, until at the end of the tenth day it enters the pupa stage after having shed its skin for the last time.

Both the larva and the pupa are not fish, but insects. They must breathe the air from the atmosphere. The larva has a tube at the end of its tail, which it thrusts through the surface of the water, and so breathes. The pupa has short tubes on its 
back through which it obtains air in a similar manner. After taking a breath of air the larva goes down again to feed. On its head are two swirling circulatory organs which direct particles of food towards its mouth; the pupa does not feed.

The pupa stage lasts, in hot weather, for about twenty-four hours; but this period may be prolonged if the water is cold. During this nymph stage, the winged insect is gradually forming within the pupa skin, much as the kernel of a nut becomes loosened within its shell.

While the pupa is resting near the surface of the water, breathing through the air tubes on its back, the skin splits where the latter meets the surface. Through the split the head, antennæ, and the proboscis of the mature flying mosquito slowly emerge above the water. The two forelegs are thrust out and rest on the water on each side of the pupa-case, making tiny dimples on the surface of the fluid. These are followed by the next pair of legs, and then the wings are born. For half an hour the partly hatched mosquito remains floating on the old pupa case, from which it is in process of being born. The wings are gently separated and carefully tried, and ultimately the body and last pair of legs are drawn out of the shell, when the new mosquito flies away. If during this process there comes a gust of wind, or the water is disturbed in any way, the mosquito will be drowned. It is a fateful period of its life.

But if there is not enough food for the three hundred larvæ in the water, they will kill each other, 


\section{LIFE AND HABITS OF DOMESTIC MOSQUITOS}

and only the strongest or the luckiest will survive to the pupa stage. They will sink all considerations of family ties in their desire to live; the strong ones will eat up their weaker brothers and sisters. In the meantime, however, if the mother returns to lay some more eggs, the first generation of children will devour their step-brothers and sisters. It is extremely improbable that both broods had the same fathermale mosquitos live for only a few hours, or at most two or three days; like silkworm moths, their lives are just sufficient to ensure the perpetuation of their species.

It is interesting to watch this cannibalism. Put some small mosquito larvæ into a glass vase holding a little clean filtered water. Look at it every day, and note how the numbers of swimming insects decrease, until at last only one or two full-grown larvæ remain to tell the tale; but these are well fed and swollen at the expense of their brethren-they have eaten them all. This cannibalism occurs only as a last resource.

Domestic mosquito larvæ and pupæ have many enemies. Chief of these are the gold-fish. An ornamental garden fountain which contains gold-fish is always clear of mosquitos; the fish eat the eggs as they are laid. But all fish do not eat mosquito larvæ. There is a domestic species of mosquito, Acartomyia zamittii, that passes its larval metamorphosis in very salt water, such as is found in the salt-pans on the seashore at Malta, Beyrout, Smyrna, and on the Mediterranean littoral generally. In the pools where 
these larvæ are found there are sometimes small fish ; but the larvæ thrive notwithstanding.

Then there is an insect that inhabits some freshwater pools and ponds. It is known as the waterboatman or "backswimmer" (Notonecta). It lives on mosquito larvæ, and will keep a pond quite clear of them. It swims on its back under the water with its face upwards, and catches the breathing mosquito larva or pupa in its jaws. It is fitted with a pair of paddles which enable it to dart about rapidly in the water; and it can hop from one puddle to another. It is a water-beetle, but is rendered powerless against mosquito larvæ when the pond becomes full of green weed, which hampers its movements.

Mosquito larvæ will not withstand drying. Pour some water containing larvæ on to some dry sand. Note how the larvæ soon stop wriggling as the water dries up, and how soon they die. They will not live in quickly running water either, for there they cannot breathe. If the wind causes a constant ripple on the surface of the water, they cannot breathe, and soon die off.

Mosquito larva have several artificial enemies also. As stated before, they require air to breathe; they must rise to the surface of the water every few minutes to obtain the necessary supply of oxygen. Now, if the surface of the water is covered with a layer of oil, the supply of oxygen is cut off. The larva then attempts to thrust the tube in its tail out of the water, but it encounters only oil. As a result it dies of suffocation. This artificial enemy, which was 
discovered by Aaron in America in 1890, is made use of largely to prevent the larvæ coming to maturity, and is thus a means of reducing mosquitos. A simple experiment will show how the oil acts. Place a little water containing mosquito larvæ into a tumbler, and watch them wriggling. Then put a few drops of any oil on to the surface of the water, and wait until it spreads evenly. Note how each mosquito larva rises to the surface to breathe, and how it tries to thrust its breathing-tube through the layer of oil-but its efforts are in vain. In half an hour all the mosquito larvæ will be dead at the bottom of the water. This discovery has been one of the many that have led to the saving of human lives.

Other artificial larvicides have been employed. An attempt has been made to posion all water containing mosquito larvæ with sulphate of copper or lime. But the former is very poisonous, and can only be used in cesspools and such-like places, and the latter forms a hard calcareous mass in the water ; both are less efficient and more expensive than oil. Placing iron nails into water cisterns is not much better. Professor Ross has recently suggested the use of cyanide of potassium. It is very poisonous, of course, but it can be made up into soluble tablets and thrown into cesspools or water collections in such a quantity that it will not hurt human beings or animals even if they were to drink it. This use of cyanide of potassium is only in its experimental stage. Petroleum is the larvicide that is commonly used. 


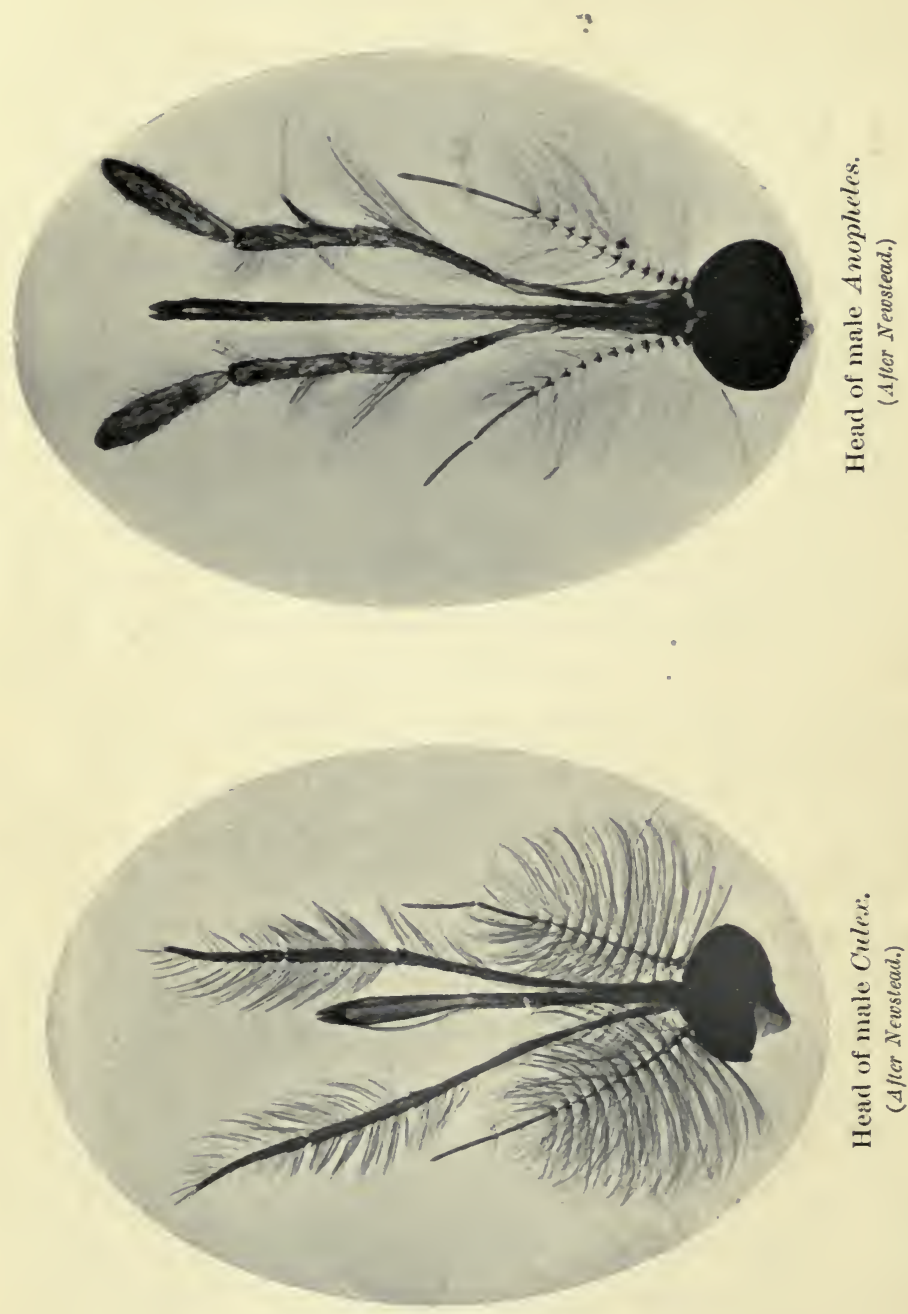

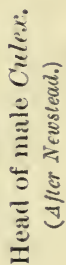

\% 
The larval stages (the larval metamorphosis includes the pupa stage) last for twelve days in hot weather. If the water is cold the metamorphosis may be much delayed-it may continue for a month or more. But eventually the imago appears. When the flying mosquito has emerged from the pupa it flies slowly to the pool-side, or perhaps rests upon some floating object on the way. It is very feeble at first and likes to rest and feed on any food it can find. It thrusts its proboscis into the water or into any sodden floating matter. Then mating takes place.

All the larvæ that have developed from one eggraft do not reach maturity at the same time. Some have had more food than others. Out of the three hundred larvæ that result from the egg-raft a very large proportion become male mosquitos. If a hundred Culex larvæ are collected, and all of them allowed to hatch into grown mosquitos and then killed with chloroform or tobacco-smoke and examined, it will be found that the proportion of males to females is about seven to one-the males of the domestic species are always the most numerous. But if a mosquito net in a bedroom of a house which is infested with mosquitos is examined in the early morning, it will be noted that there are only one or two males and perhaps twenty or thirty females resting on the curtain. It is easy to distinguish them. In the domestic species, the males have plumed heads - their antennæ are bushy and their palps are long. If so many males are hatched from the eggs, how is it that they disappear so rapidly, or are not found in 3 


\section{LIFE AND HABITS OF DOMESTIC MOSQUITOS}

the bedroom? The answer is that male mosquitos live a few hours only to fertilise the females, while the latter may live for months. Further, male mosquitos do not require blood for food.

Since there are so many more males than females, it must be very rare for the female to escape early fertilisation. The males remain near the water collection and catch the females as soon as they are hatched. With the more rural species it is different. These are hatched out singly from the more isolated eggs, and the larvæ are consequently likely to be more widely separated in marshes and large collections of scattered water. In this case, one sees, on hot, still, summer evenings, swarms of males flying over cultivations and gardens. This is done probably to attract any newly hatched females that may have wandered or are playing truant. Coitus takes place either on the wing or when resting. One male may fertilise several females in succession. At each coitus, the three spermathecæ of the female are filled with spermatozoa, unless the mosquitos are disturbed in the act. These spermathecæ are spherical, inelastic chitinous bodies situated in the last abdominal segment of the female; they can just hold the number of spermatozoa requisite to fertilise all the eggs laid in each brood. If a female lays a whole egg-raft or complete brood, she exhausts all the spermatozoa within her spermathecæ and then she must again cohabit with a male in order to be replenished. This is the reason why males are likely to remain in or resort to the places where the females commonly 
lay their eggs. For example, in houses, the males of the Culecines are commonly found in the waterclosets. The females are attracted there by the sealwater, for they know that their children will thrive therein; and also that as soon as they have laid their eggs the males are ready to refertilise them again. The eggs exude their larvæ into the sealwater of the closet, the latter are washed down into the cesspool where the water is at an even temperature, and where there is plenty of food for them; so the perpetuation of the species is assured. As the female lives so much longer than the male, her second and third fecundations are brought about by the males of succeeding generations to her own. This is why males remain near the breeding-places, and their presence in a house is a sure sign that the larvæ are near-probably in the cesspool of the house. In any tropical town, when a cesspool is opened, thousands of mosquitos fly out. In Egypt these cesspools were the chief breeding-places for the domestic mosquitos.

A female mosquito having partaken of several meals of blood, and having her ovaries full of matured ova, goes in search of some suitable water collection where she can lay her egg-raft undisturbed, and where she can be certain that her larvæ will thrive. She naturally returns to that collection of dirty water where she herself passed her own larval metamorphosis; for she knows that the water will be suitable for her purpose. After she has laid her eggs, she will find there males of her own species, but 


\section{LIFE AND HABITS OF DOMESTIC MOSQUITOS}

of a later generation to her own, for her refertilisation. Consequently it must be realised that domestic mosquitos will not fly far from their breeding-places, for if there is plenty of food near, there is no reason why they should. It can hardly be expected that mosquitos will fly from one part of a town to another; merely to gratify a whim of geographical curiosity. This is a matter of the greatest importance, and it has been proved experimentally, for it has been found possible to prevent mosquitos in one part of a town while they continue unchecked in another; even then they will not fly into the cleared district.

Objections have often been raised against proposed anti-mosquito campaigns, that mosquitos will fly in from the uncleared districts round about, and so render the campaign futile. This is not true. Mosquitos do not fly far, for the reasons given above. Limited campaigns have been instituted as an experiment in small portions of large cities, and so long as they were conducted properly they were successful. Port Said and Cairo were examples of this. If, however, there happens to be a swamp that is breeding mosquitos outside a town, and there is no food near which the fertilised mosquitos can obtain readily, then a few females will find their way into the town; but their numbers will be very small. An occasional mosquito is conveyed by trains and ships, but the numbers never seriously affect a cleared district. Such objections are only raised by lazy administrators.

To summarise: The fecundated female mosquito 
must return periodically to a suitable water collection to lay her eggs, and to find another male. The larva spends twelve days in the water. If the mosquitos in a town are to be reduced it is obvious that this is the time to attack them-when they are in the water and can be easily reached. It is very difficult to try to catch and destroy the flying insects, and it is rarely necessary except in sudden outbreaks of yellow fever. Flying mosquitos can be dealt with by fumigation, and the yellow-fever patients must be screened during the early days of illness; but these are special measures to be undertaken against this disease.

Flying mosquitos have certain natural enemies like the larvæ, but they are rarely efficacious in reducing the numbers of the insects. The chief of these are birds, bats, and lizards. Cold also kills numbers of imagines, while some of the females hide in dark corners and warm rooms, and hibernate throughout the winter. The best and the cheapest method of reducing domestic mosquitos in a town undoubtedly is to destroy them when they are larvæ swimming in the water. 


\section{CHAPTER III}

THE FEVER CENSUS

When public money is spent on any municipal improvement, after a time people are inclined to ask: What are the results? This is also the case with health measures. Unless the state of health of the town is known before the sanitary reform is begun, it will be impossible to obtain comparative statistics, and there will be no means of showing what the results are. This may cause those responsible for instituting the reforms to render themselves liable to deserved criticism. Statistical results are always expected, and every effort should be made to obtain them. Unless inquiries are made before the reform is started it is very difficult to obtain correct figures afterwards-and statistics, to be of any value, must be comparable. It is most important that any figures obtained at the outset of an anti-mosquito campaign should be checked regularly and periodically with those obtained during its progress, and compared with them, and corrected so that the methods employed may be modified or improved whenever necessary or practicable. In this way only will it be possible to state, as numerical facts, the 
results obtained, and to justify the expenditure incurred.

The first step to take is to try to find out the common diseases present in the town, and their individual prevalence. The best person to do this is the local health officer, if there is one. The medical officer of health of a town must be already conversant with the diseases that cause the death-rate. $\mathrm{He}$ is in touch with all the local medical practitioners, and has regular access to the death registers and examines the death certificates, if there are any.

But health officers, especially in warm climates, very frequently suffer from the belief that their duties consist solely in preventing and dealing with epidemics, and they are often inclined to ignore those endemic diseases which may and frequently do cause, both directly and indirectly, the high death-rate. A hot climate, in itself, does not produce an excessive mortality ; it is always due to disease. For instance, since mosquitos have been abolished the mortality at Rio is the same as that of Liverpool. There is another example. The Health Departments in Egypt have spent $£ 249,000$ during the past few years on the "prevention" of plague by an out-of-date method. About 900 cases of that disease occur in a few scattered villages every year; but in spite of the so-called prevention, the disease continues as before. On the other hand, some thousands of children die of the effects of measles in the cities of that country annually. And yet for this disease the Health Department has not spent a penny ; and in January 
1910 the same Department objected to subscribing $£ 300$ towards the anti-mosquito campaign at Port Said which had had excellent results, and which had been the means of reducing the general death-rate in this formerly insanitary and unhealthy town. The reason given was that the Egyptian Government could not afford to fight endemic disease, but must expend all its energies on epidemics. They had already expended energy to the amount of nearly $£ 249,000$, and the result was nil; but they refused $£ 300$ towards the upkeep of a result that is well known and obvious. These facts are mentioned here because they serve to show that the fight against diseases that are slow but sure in their action is not always encouraged by those whose duty it is to wage the war. The reason is that there is less credit to be obtained by fighting chronic and slowly killing fevers than by dramatically "preventing " an epidemic of which there was never much danger.

But it is not always easy to gauge the exact amount of fever that exists in a town; nor the exact nature of that fever. Even the local health officer may find it difficult to discover how many cases of malaria occurred during any one year, how many persons had typhoid, how many dengue, what was the incidence of simple continued fever, or of the recently discovered three-day fever. How is he to distinguish between them all ?

In the present state of our knowledge one cannot be certain of doing this. It is only possible to compare one year with another-hence the importance 
of comparable statistics. If the health officer can compare the total number of cases of fever notified year by year, before and after the mosquito campaign is started, all well and good. But he cannot always even do this. There are many tropical towns -there are many European towns-in which no health statistics are or ever have been kept. He may have to find out the details of disease incidence for himself.

He should examine the death registers, if there are any. He will find that it is diarrhœa and broncho-pneumonia that kill the most; many infants have died of these two diseases. Then he will notice that many old people have died of pneumonia and bronchitis, apoplexy, and dropsy - a few of old age. But frequently there will be some deaths marked in the register, "Fever"; and this is especially noticeable in India. What are these? Are they all malaria? It will lead him to inquire into the accuracy of the methods of registration. This will open his eyes. In England, practically every death that occurs is accompanied by a certificate signed by either the medical practitioner who attended the case in the last illness, or by the coroner; and the cause of death is written on that certificate. But in countries where there are many natives such certification is unusual. Most of these natives die without medical attendance-their relatives can rarely produce a medical certificate. It may be the custom to send a doctor of the Health Department to view the corpse in order to see that death has not been due to 
plague or cholera; but this is not much use, for it is difficult to say what a man died of by merely looking at his skin. The Arab knows only one cause of death ; it is, "God willed it that the heart should stop." In India one may see in the death register"Plenty much belly pains." But these are not very scientific causes of death. Even suppose a death is certified as fever, it is rarely stated which fever. Some, but not very much, knowledge can be obtained from the death registers; even the little gained is rarely reliable.

The health officer should apply to the doctors. If there is a local medical association or institute he may utilise it for the purpose. Or he may write a circular letter to all the medical men practising in the town, inviting them to inform him of such cases of fever as come to their knowledge ; but it is necessary to explain to them the reason for the demand. Experience shows that it is better not to make fever a compulsorily notifiable disease. It is very tiresome for any medical practitioner to be constantly filling up and posting notification forms ; in many countries there is no compulsory notification. Then a medical man may notify a case as fever, and it turns out to be appendicitis, and he is obliged to correct his diagnosis; this gives him extra trouble, and it vitiates the returns. It is better to ask them to send in a biennial list of all cases of "fever"other than typhoid, typhus, Malta fever, or tuberculosis, to the health office. This gives less trouble to the practitioner than regular notification. He can 
make up his list from his books when he draws up his accounts. If possible, it is a good plan to have a number of forms typewritten (or printed, if there are funds available) with columns dividing the fever incidence into three categories-three-day fever, sevenday fever, and fever of longer duration. Under each heading the doctor can enter the number of cases treated by him which come under these categories. One of such forms can be sent to each practitioner at every half-year, or just before each quarter-day, as convenient to them.

The books of the hospital and dispensaries should be examined. Much valuable information can be obtained in this way. A clerk can easily count the number of in-patients treated for "fever" during five years. He must exclude typhoid and the others, and he can place malaria and yellow fever in another list. Then he can obtain the bed tickets and temperature charts of those patients who suffered from fever, from the registrar or secretary. These may be sorted out and separated into groups similar to those mentioned above-namely, three-day, seven-day, and longer fever. The out-patient and dispensary books also will probably show a number of cases marked as "fever." This diagnosis may include early typhoid, malaria, measles, influenza, and many other affections, but still the figures obtained may be useful for comparison in future years. But in all cases it is important to note at the same time the total number of cases treated every year both as in-patients and out-patients; then the sick-rate can be obtained. 
Some doctors dislike imparting information concerning the total number of patients treated by them, and their wishes in this should be respected. The percentages obtained from the hospital and dispensary records do not suffer from this disability. There will soon be a list showing that out of a number of sick persons treated in the town there were so many that had suffered from "fever," and these cases of "fever" are classified.

Similar inquiries should be made from the employers of regular labour. From factories, workshops, dock-boards, stores, municipal stables, police barracks, offices-anywhere where a number of people are employed. The owners and managers of such establishments and organisations must be approached carefully, however. They are very liable to become frightened at the approach of the health authority ; and their fright will exhibit itself in reticence. They will not hesitate to make exaggerated statements concerning the health or the reverse of their workpeople, if they think it will be an advertisement, or will save trouble. For example, the manager of an hotel will rarely speak out about the health of its visitors. So, too, with the manager of a workhouse, or the director of a reformatory or prison. The health officer must be tactful in such matters, or he will find a closed door. It is better to deal with the medical advisers to such establishments if he can. If this is not possible, he must first advertise his reasons for making the inquiries. Let him put a notice in the local newspaper asking 
people to co-operate with him. If a thought of the General Medical Council, or similar body, raises a quake of fear in his mind, let the notice in the journal emanate from the secretary to the municipality or some such corporation. Anyhow, let his intention be advertised. People will largely co-operate if they see the sense and sincerity of the purpose.

Lastly, let him inquire at the schools. Each school should be visited. How many scholars are there? How many attend regularly? How many are absent during the year, and for how many days ? At what time of the year are the absentees the most numerous ? Remember that the masters of private schools may extol the healthy condition of his pupils. It is better to examine the books, if possible. Why in one school are there more children absent than in another ? This is the subject for his inquiry. Have they had fever? If so, what fever? It is guaranteed that the health officer will soon learn matters that he never realised before concerning the health of his town. In all cases let the figures be written down, and carefully kept.

There will soon be a collection of interesting observations that may be correlated. The population of the town is known. Inquiries have been made concerning a number of persons of both sexes, of all ages and degrees of life, of schoolchildren, policemen, labourers, and workgirls; and of these so many have had fever of some nature or other during some period of the year. Then the doctors will give him the lists showing the number of sick people treated by them. 
that suffered from fever of various kinds. In this way the percentages of fever incidence can be obtained. These percentages can be checked by the figures obtained from the hospital and dispensaries. If the inquiries have concerned a sufficient number of persons, there will only be such a small statistical error that it can be ignored; but this error may always be discovered by the Pearson-Poisson formula-a formula that is well known to all students of vital statistics.

But how is it possible to discover the exact nature of the fevers that occur in the town? How can it be known that any of them are conveyed by mosquitos ? It may be stated that this question cannot be answered at once in the present state of knowledge. Fevers in warm climates have not yet been completely classified. The returns will include all sorts of fevers of various origin. But if the figures obtained before the mosquito campaign begins are compared with those obtained from the same sources and in precisely the same way afterwards, when the mosquitos have disappeared from the town, a difference will be noticed-a marked difference. If the campaign is carried out properly, the mosquitos will disappear rapidly; but the fevers will disappear even more rapidly.

If there is no health officer, an official may be appointed by the municipality or any local authority, or even a community of residents, to undertake the mosquito campaign, and to carry out the fever census. A medical man is the best person to do this, of 
course, but it is not absolutely essential. In a small community, any responsible person who has the sympathy of his fellow villagers can undertake the measures recommended in this book.

If, when making the fever census, it is discovered that there is actually malaria in the town, then a spleen census must be taken, and the disease stamped out as promptly as possible; the methods are fully described in Professor Ross's book, "The Prevention of Malaria." Or if there is yellow fever, Sir Rubert Boyce's "Mosquito or Man" gives all the information required for fumigation and isolation, and for successfully dealing with the disease. 


\section{CHAPTER IV}

THE ESTIMATE OF THE COST

Reforms of almost all kinds cost money, and sanitary reforms are no exception to this rule. But as health is cheap at any cost, the extra expenditure is well justified when a mosquito campaign is proposed. Unnecessary extravagance, however, must be avoided. Mosquito reduction is not an expensive measure, but it cannot be done for nothing. Some money will be required; and the question is-How much?

The cost varies in different localities and is dependent upon several variables. Thus, the size and population of the town or village, and the size and congestion of the houses. Then the presence of cesspools and their individual extent, the efficiency of any sewers and street drains, the means of storing water in houses in water-butts or cisterns, and the presence or absence of rain in the hot weather. In addition to these, the important factors are the price of labour and the cost of oil.

The influence of these variables is well shown by the difference in the cost of the mosquito campaigns in the two neighbouring towns of Port Said and Ismailia. In the former the cost is only sixpence per 
head of population per year, while in the latter it is nearly two shillings. This difference is largely due to the many regularly irrigated gardens at Ismailia, which have to be dealt with every week. But the comparative size of the two towns is also an important factor in producing the difference in the cost of the two campaigns. It may be taken as a general rule that the larger the town, the less, relatively, is the cost per head of population per year; and at the same time, the more scattered the houses, the greater becomes the annual cost of the work. Thus Port Said is a compactly built town of 50,000 inhabitants, whose houses are closely packed together, while Ismailia is an openly built village of $\mathbf{1 0 , 0 0 0}$ people only.

In dry summer climates, such as that of the Mediterranean littoral, it may be accepted that a campaign against domestic mosquitos will cost $£ 1,000$ a year for each 50,000 inhabitants in towns having less than 250,000 population. In towns having less than 25,000 inhabitants the cost will be relatively greater, while in those over 250,000 it will be relatively much less; but the scale is a geometrical one, and cannot be estimated in arithmetical proportion. However, a municipal rate of sixpence per head of population per year should be sufficient for the upkeep of a mosquito campaign in towns and cities having a population of more than 25,000 inhabitants ; but this rate may have to be increased owing to summer rains or floods, where there is no drainage or outflow for the water over an impermeable soil, or if there is much 
irrigated land, many parks and public gardens, birkets or large ponds. On the other hand, it may be decreased, as stated before, by a well-arranged drainage system, provided that the flush is ample and constant. Shortly, if there is much water that remains stagnant for more than a week at a time, the cost of the domestic mosquito campaign will be proportionately greater.

The estimate given above does not include major sanitary works, such as the filling in of marshes, pools, borrow-pits, birkets, and such-like collections of water suitable for mosquito breeding-places-the cost of such measures must vary considerably in different countries; but these are ordinary sanitary measures and should not be placed to the account of the mosquito work alone, as has so often been done. It is a mistake to include such municipal expedients in the budget for the mosquito campaign, for then committees are liable to dismiss the whole project on account of its great initial cost, forgetting that it is the duty of the State to undertake permanent reforms that lead to health. The estimate given above is for the upkeep only of a regular anti-mosquito campaign, and large town-planning schemes must not be included.

Such an estimate is, at best, a rough one. It is better to make a careful house-to-house examination of the town, noting exactly where the mosquitos are breeding, and estimating directly the cost of dealing with them. It is not a very great undertaking, and will well repay the energy expended. Take a survey 


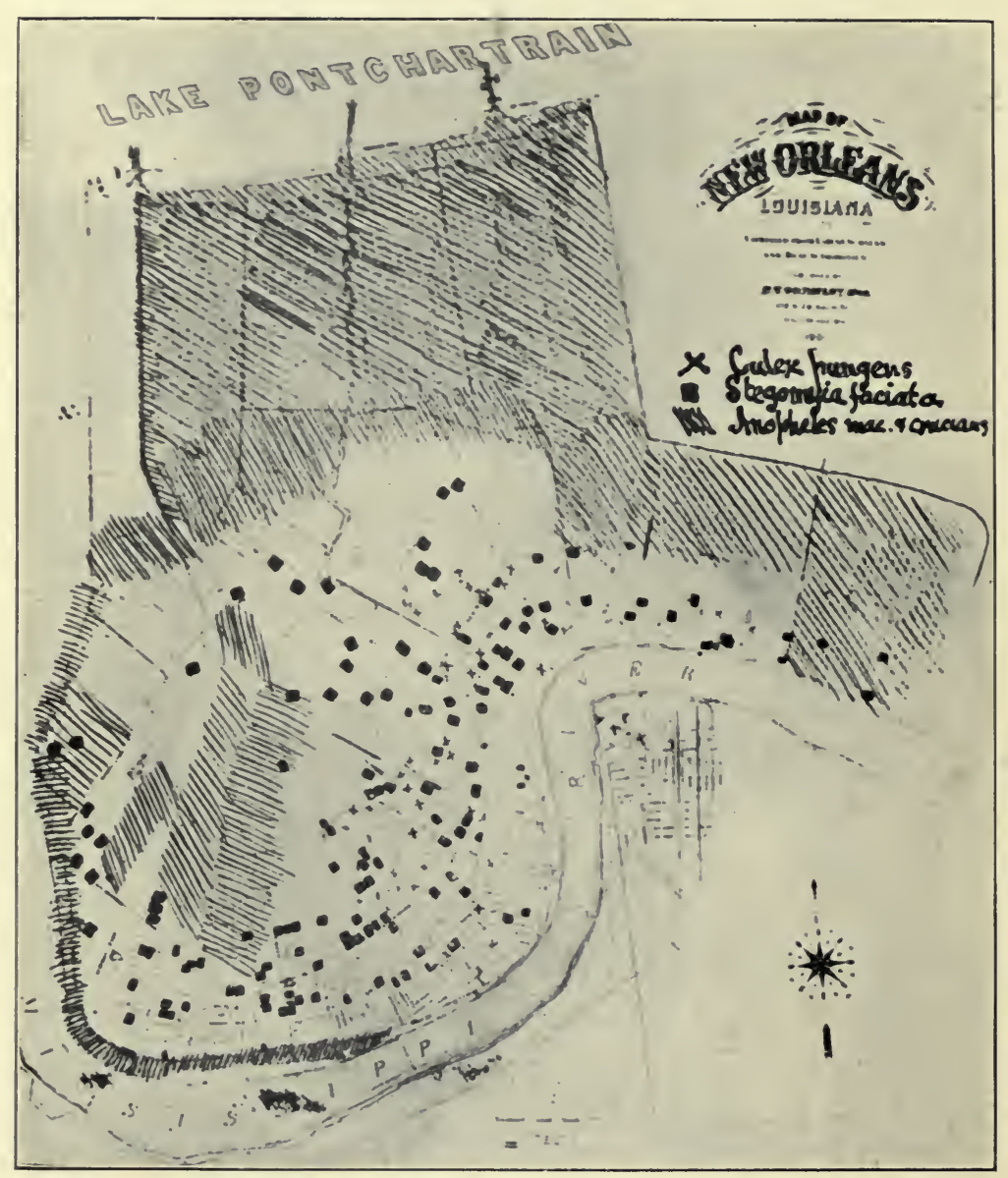

Plan of breeding-places of domestic mosquitos at New Orleans. (After Boyce.) 
map of the town-if one cannot be obtained, make a sketch-map-and rule it into squares. The squares should be of equal extent as far as possible, and their total should include the whole area to be dealt with. Begin at one corner and examine all the houses in each square street by street. Write in a large notebook the name of the streets and the number of each house or hut, if they are numbered. If there are no numbers or names, write the name of the proprietor of each house and a tenant. This examination should be made during the height of the mosquito season, and immediately after heavy summer rains, so that the estimate may be made during the period of maximum density of the insects. During this examination a careful inspection must be made of all backyards, and every cesspool should be opened. The presence or absence of mosquitos or their larvæ should be noted, and the extent of the water surface which contains them. The number of garden fountains, water-butts, cisterns, ponds, garden puddles and pools should be counted, and the presence of mosquito larvæ or pupæ in them observed and written down.

At the end of the house-to-house examination of the town the number of square metres of water surface can be added together-a water-butt may be estimated as having half a square metre of water surface. Then, allowing one litre of mixed oil for each square metre of water surface per week, and multiplying by fifty-two, the exact estimate of the amount of oil required per year will be obtained. 
The best larvicide for mosquitos is the abolition and prevention of stagnant water collections; but the second best is the use of oil. Cesspools should be replaced by a sewerage; local marshes ought to be drained, or filled up and reclaimed; infiltration water collections levelled; and house-tanks and water-butts dispensed with by a better, or more constant, pressure of water on the town mains. But while such municipal reforms are being carried out or discussed, the reduction of mosquitos may be conducted by the use of oil as a larvicide.

The oil most commonly used for this purpose is petroleum. In Egypt equal parts of refined and crude petroleum mixed together is generally used. As a matter of fact, any oil may be employed, as already pointed out, for it is the mechanical action of the oil resting on the surface of the water in an even layer that suffocates the mosquito larvæ, and not any poisonous effects. But petroleum is usually the cheapest, and the oil commonly used for this reason; it is also obtainable everywhere. But even petroleum is expensive when used in large quantities. Its cost varies in different countries, and in different localities of the same country. For example, at Cairo the mixed oil costs sixpence per gallon, at Port Said it is a trifle less. When the mosquito campaign was first started in the latter town, the crude oil was more expensive than the refined, because the latter was imported "in bulk" in tank steamers, while the crude petroleum was only brought from the East Indies in small quantities at a time, and the freights 
were high ; as it came more in demand, however, its price fell somewhat.

But if it is known how much oil is required per year, an estimate can be demanded from the various local merchants, and the lowest tender accepted. If there is any cheaper kind of oil on the market it may be employed as the larvicide. "Elephant oil" is quite efficacious as a mosquito larvicide, but it is liable to become thick in cold weather, and will require mixing with such a large quantity of refined petroleum in order to spread well on the water, that there is little or no saving of money.

Facilities for the supply of oil can be obtained in every town, but in some countries the presence of oil depots are prohibited near dwellings. In this case allowance must be made in the estimate for the regular transport into the town every day or every week as convenient.

The amount of oil required per year and its cost having been estimated, the next thing to do is to count the number of days which were required to make the house-to-house examination of the town by one person. From this it is readily calculated how many men will be required to visit similarly every house and garden in the town once every week, excluding Sundays. Then, the price of local labour being known, the annual cost of the number of workmen required can be readily determined. If the town is a large one these workmen should be divided into gangs, each controlled by an overseer or foreman. Each gang should consist of three or four men, and 
their work distributed fairly and evenly. The usual pay of such men can be found but by application to any large employment contractor or agency.

The cost of the oil likely to be required per year will thus be known, and also the cost of labour and the necessary staff. It only remains to estimate the price of one oil cart for each gang, overalls for the men, and to make allowance for repairs, and for sickness among the foremen, etc.

In this way exact estimates for an urban mosquito campaign should be drawn up. If there are many constant rain-water puddles in which the water commonly remains stagnant for more than a week, and these cannot be readily drained or filled up, provision must be made in the estimates for dealing with them regularly, like other permanent water collections. Mosquitos require at least twelve days in water to pass their larval metamorphosis even in the hottest weather, and the mosquito larvæ will not stand drying; this knowledge must always be borne in mind when the question of collections of rain-water is being dealt with.

As stated before, this method of making the estimate is not a very great undertaking; and there is the satisfaction of knowing that it is correct, and that there will be little likelihood of the necessity for subsequent requests for further grants. If there is any doubt on this point it is better to make an estimate in excess, for constant demands for supplementary credits are always a source of annoyance to administrators and councils. 


\section{CHAPTER V}

\section{WAYS AND MEANS}

The fever census having been taken, and the cost of the projected domestic mosquito campaign estimated, it remains to find the money to start and to defray the regular upkeep of the work. The question arises at once-Who is to pay?

It is the duty of that organisation of the community that safeguards the public health to institute, and to maintain, all measures that will improve the condition of the people of the community. The neces sary means must be supplied by the local authority of the State-for this is the business of the State. But it must also be brought home to such organisations that such measures are necessary; otherwise the local authority will object to the expenditure of the public money-and rightly, for it is also the guardian of the public purse.

The health officer should draw up a report. It should give details of the death-rate, of the sicknessrate, and of the prevalence of fever as obtained by the fever census. Then the prevalence of mosquitos in the town should be described and their chief breeding-places, and the proposed method of dealing 
with them. The probable results should be outlined and the work done elsewhere described. The brilliant results obtained in the rainy Federated Malay States, on the Panama Canal, or the almost rainless Suez Canal and Khartoum can safely be quoted. The estimated cost should be set forth and the report should be printed and circulated. It will not be a costly matter, and the local health office can usually find means for doing this. Or it can be typed, or even written if the town is a small one, and then sent round to all the influential citizens. If there is an urban council of any kind, each member should be supplied with a copy, and the local journal convened to assist.

If there is no local authority which can supply the necessary funds, recourse must be had to public subscription, unless some private corporation is willing to undertake the work for a charitable purpose. But to pay for an established public reform by an intermittent general subscription is always an unsatisfactory proceeding; and to leave it in the hands of charity is immoral. The work is to be done for the good of the whole community, and it should be paid for by that community.

The State then must produce the necessary funds, and it probably will do so if approached in the right way. If the report is drawn up well, and the idea is backed by influential persons, the State can hardly refuse its support. If it does refuse, such a refusal will be based on the plea of economy. But the plea of economy is a poor pill to give a sick town, and few 


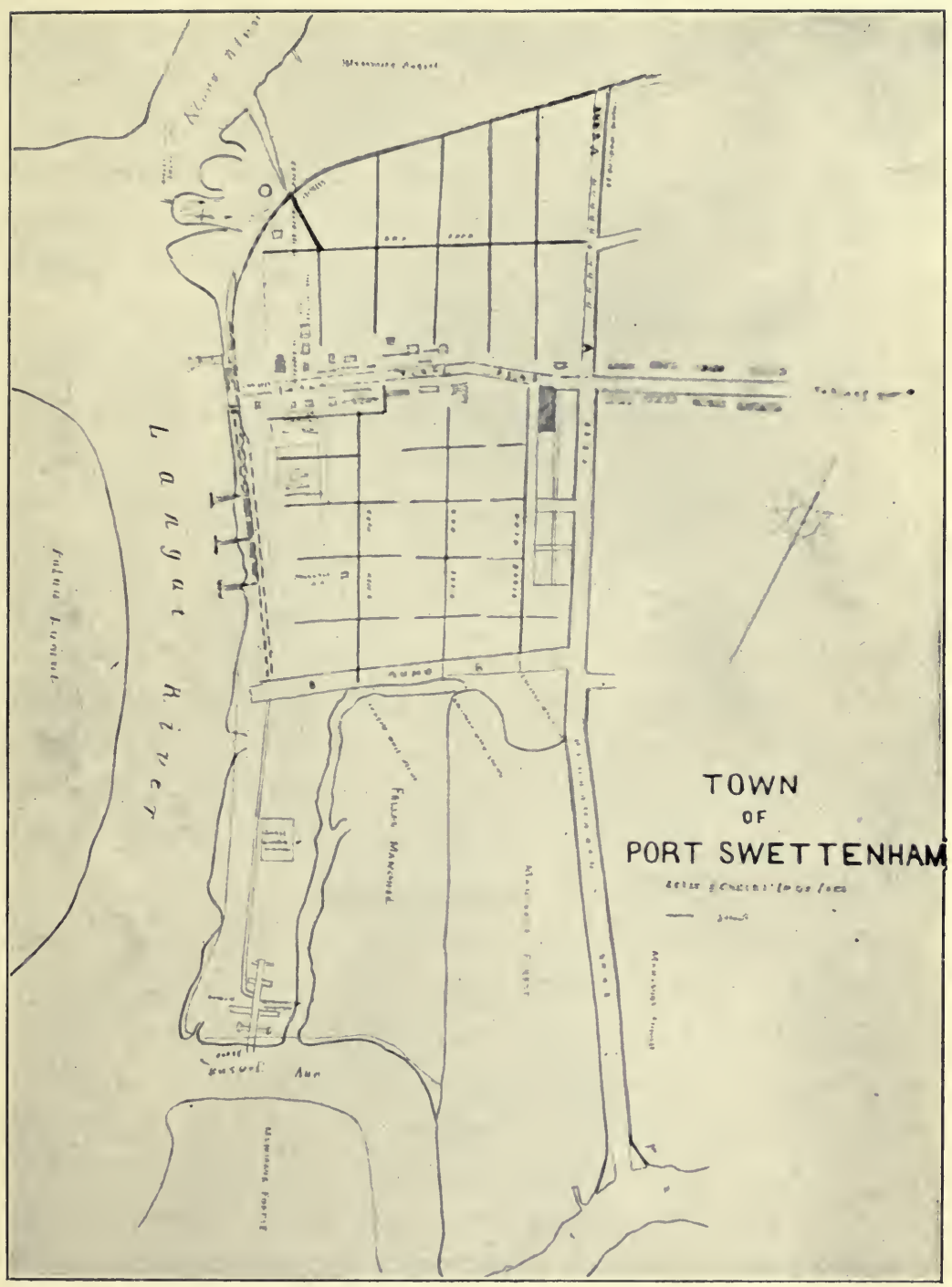

Port Swettenham in the Federated Malay States. Now cleared of mosquitos'and thealthy.

p. 56]

(After Watson.) 

such towns will tolerate it for long. If the State refuses to do its duty to the public it will soon become unpopular; an unpopular Administration does not last. These are points to be remembered, and efforts should be made, if necessary, to impress their importance on backward corporations, Government departments, etc.

There is rarely necessity for such hints, however, and the money will be forthcoming if the demand is reasonable, persistent, and sensibly made. If the estimate is carefully drawn up, and the desire to do the work sincere, the necessary means will soon appear. Financiers are, perforce, sensible people, and they like to be assured of some return for their money. Suppose a corporation of a town is invited to vote $\mathfrak{f 1 , 0 0 0}$ a year in order to reduce mosquitos, it will naturally ask what the return will be. The longvexed question of municipal trading has been settled in its favour, and local governing bodies like to be able to report that such-and-such a public work has brought in such-and-such a percentage on the capital expended. $£ 1,000$ per year represents a capital of over $£ 30,000$ which must be set aside for this mosquito work. Where is the dividend? How much per cent is it, and when will it be paid? What is the return? These are the questions that will at once arise.

The same financiers will say that credit is almost as good as an actual asset-by some it is considered more useful. A town with a bad name for being unhealthy has no asset, and it has no credit. It has no trade, there is no business going on-people who 
live in it are always ill-there is nothing doing, and its population will not increase, "no matter what its position or its natural advantages may be. Nobody will invest money there for building or trading, for tramways or amusements; and the place will soon be at a standstill. It commands no credit, and it has no asset-it is unhealthy. But if the town is made healthy, then money will soon flow in, and its credit will advance and become cheaper as progress replaces the condition of standstill. Then the expenditure will be justified, and the sunken capital will not be grudged or cavilled at. These truisms must be emphasised ; the results obtained at Havana, Rio, and New Orleans can be quoted with assurance.

But should it be found impossible to obtain funds from the State, a public subscription must be raised. Then, if the work is successful, the State can again be approached to take up its share of the burden. However, as mentioned before, public subscripton is not very satisfactory. Public-spirited persons will subscribe for a time. They may find mosquitos a terrible pest in their houses, or they may find their children constantly ill, or their occupations suffering through their ill-health, or the constant sickness of their employees may be costing them money or hurting trade; then they will subscribe. But a time will come, after the mosquitos have disappeared, and are forgotten, when the subscribers will fail in their support of the cause, or a new generation will grow up that knew not mosquitos, and it will not pay. At first they will forget to subscribe, then they will grumble, and at 
last they will refuse; and the mosquitos will surely return. But it is most disappointing and may be heartbreaking, for all the trouble and energy expended will be for nothing; but not quite, for something will be learnt from the lesson. Perseverance and again perseverance-this must be the motto always. Begin again, and try the State once more.

If subscription is the only course that can be adopted, it can best be carried out in the following way. Advertise in every direction the nature of the work to be started. Institute public lectures, distribute fly-leaves describing what is going to be done, the reason for it, the estimated cost, and the probable results. Talk about it to influential persons, and prove the sincerity of the purpose. Then open a subscription list at the banks and post offices. Get up a fête or a ball or a theatrical performance on its behalf. Write to the local papers. Interest the large trading-houses, the doctors, the local exploiting companies, the schoolmasters, the clergy. Keep open the subscription, and canvass. It is worth it. There can be no better charity than this. But let very careful accounts of money received and expended be kept. Balance sheets must be published regularly, and the names of the subscribers and their subscriptions registered, so that the same may be applied to again and the results reported to them.

Public subscription is a course that is not advised unless it is found impossible to raise the necessary means in any other way. Therefore it should only be regarded as a final resort. Mosquito reduction is 
such a boon and a blessing to the whole community, and as it is one of the most popular of all sanitary measures, the money can generally be found for it if sufficient energy is expended in propounding its possibilities, and a real effort is made to carry it out. It has been successful elsewhere, and, if properly continued, it never fails. 


\section{CHAPTER VI}

\section{PRELIMINARIES}

When the estimate is approved, and sufficient money for the start has been found, the first preliminary is to state publicly the nature of the work-the reason why it is to be adopted, the method to be followed, and the result it is hoped to obtain. This is best done in the local newspapers. It should be advertised that the intention is to reduce the number of mosquitos, and with them the incidence of fevers. Ask for the general co-operation of the public. Then write again and describe how the work is to be carried on continuously. Relate how mosquitos breed, and pass their larval lives in dirty water; how it is proposed to reduce the numbers of the insects by attacking them during their lives in the water. Describe the methods. There must be no mystery about it. Ask boldly for permission to enter every house in the town once every week for the purpose of killing mosquito larvæ. State the estimated cost. Mention where the money is coming from. Remind the readers of successes elsewhere. The editor of the newspaper should welcome this as good "copy"; and if a correspondence is started concerning the project, so much the better. 
Many sanitary reforms are started badly. It is common to find health officers: beginning important health reforms with a long proposal containing a tiresome schedule of irritating by-laws to be passed by the town council. The by-laws are bound to tread upon the toes of somebody. Then ensues an endless discussion. Lastly, the object of the proposed bylaws is forgotten in the heat of party strife. Little can be done by such means. The writer has witnessed a comedy in which a bacteriologist memorialised a Committee, consisting largely of natives, demanding $£ 50$ for the destruction of twenty goats which had Malta fever. But the memorial was so full of "terrible technical terms" that the proposal was negatived before it was read. It was not understood. Malta fever continues there as before.

The reduction of domestic mosquitos is best conducted without petty rules and regulations, which only irritate householders more than mosquitos, and persecute the proprietors of property. Afterwards, if a new by-law is urgently needed it can be brought forward with experience to back it up. But at first new legislation should be avoided. Advertise the nature of the proposed work, and state emphatically that it is going to be done. Have confidence, and then do it. In many countries the sanitary authority has not the power, without endless formality, to force his way into houses with a view to finding out insanitary conditions. The only way to overcome this difficulty is to advertise openly that it is the mosquitos that are going to be attacked, and not the 
tenants. In this way the difficulty will be speedily overcome. The inhabitants of a town will give way to the weekly visit of the sanitary authority if they realise that they are to be rid of the pest of mosquitos-especially if they are not asked to pay for it directly; but if they think that as a result they are going to be haled before a judge and bench, crossexamined, fined, and perhaps impaled, they will, very naturally, object and oppose the proposition. Here, then, is the reason for the advertisement. Obtain the assistance and co-operation of the doctors and the goodwill of all the influential residents, and then opposition will vanish.

At Port Said there is a law forbidding all Government servants to enter any house under any circumstances whatever; the sanitary authority had no power at all-he could not venture off the streets, he could do nothing. The difficulty was overcome in the way described. The mosquito campaign was advertised, and then the landlords and tenants gave their permission to the men of the mosquito brigades to enter their houses whenever they liked for the purpose of reducing the objectionable and unpopular mosquitos. As a result, the sanitary authority enters every house in the town once every week at the request of the inhabitants, and he can now go ahead with sanitary reforms. The result is well known; but it may be stated here that although the work has gone on continuously for five years, there has not been a single complaint against it, although the law mentioned above still exists. The men of the mosquito 
brigades enter every house in the town regularly every week. In consequence, : cesspools and basements have been rebuilt, houses rendered more sanitary, the death-rate has fallen, and mosquitos and fevers practically abolished; and there has been no opposition. But no sanitary by-laws have been enforced-there are none to enforce. Persuasion must be the keynote. Do not force, but persuade. Port Said contained among its inhabitants the most ignorant and perhaps the lowest form of humanity - both European and native-extant. Yet their opposition and prejudice to sanitary matters and measures were overcome by persuasion-not by force. We could not force-we had not the power. There are no sanitary laws in Egypt worthy of the name. We were forced to persuade.

The next preliminary is to engage the personnel of the mosquito brigades. The foremen must be respectable men; and there should be one for each gang of workmen. It is better to begin with one gang first, consisting of a foreman and three or four men, and to confine their work to one small quarter of the town. Then, when they have learned the work, to extend operations with another gang, and so on until the whole town is being completed every week, and every house visited.

Apply to some local labour contractors and tell them of the want. Ask them to recommend a respectable and honest man for the post of " moustiquier," or foreman. Preference should be given to a man living or having a family in the town; one who 
is known in the place. In Egypt a local Greek or Syrian was generally employed; one who owned a small shop or house for his family, and who had been a resident for some years. Such a man is less likely to become dishonest. Find out the rate of pay of such a man. At Port Said the foreman of a mosquito brigade is paid at the rate of $£ 5$ per month. The rate of pay will vary, of course, in different countries. But it is better to pay a little more, if funds will permit, to ensure getting a good man. The foreman should give up the whole of his time to the work. He should be engaged by the month and paid monthly. His services should be permanent, subject to his good behaviour. All the foremen, no matter in what part of the town they work, should be on an equality; good service should be rewarded by an increase of pay, but for punishment it should be liable to stoppagethe greatest penalty being dismissal.

The workmen should be labourers; natives are generally employed. Their honesty is the most important factor. They should also, therefore, be respectable and sober men. The engagement of idlers and loafers should be avoided. They should be engaged on daily pay, which can be paid to them weekly or fortnightly as arranged or convenient, so that any one of them that misbehaves can be discharged at a day's or a week's notice. Both the foremen and the workmen will have opportunities and temptations to be dishonest, and there must be the means of dealing with such cases summarily. But if care is taken to select good men at the outset, much worry and trouble 
may be saved. There is nothing that does more harm to a work of this nature than the personnel contracting the name of being lazy or dishonest. If it is possible, it is better to pay a little more to obtain honest men, and thus to avoid constant accusations of theft or charges of petty pilfering against the men forming the mosquito brigades.

The foremen and the men should not be frequently changed. The idea is that they should become known and respected in the town by the householders as the men that prevent mosquitos. Every one should know them, and who they are. Therefore engage good men and keep them. They will be required to work every day from 7 a.m. until 5 p.m., except Sundays, which are holidays ; but should mosquitos reappear, they will be required to work overtime.

The oil should be supplied by contract. The amount required per year is known. This amount should be advertised for, or the various oil merchants written to for quotations. Then these quotations may be considered impartially; that one adjudicated the cheapest may be accepted. A written contract or agreement should be drawn up by which a certain amount of oil-refined and crude-is delivered at a particular place agreed upon, daily, except Sundays, during the year at a regular price. It is better to settle one place, such as a disinfecting station, where the oil can be delivered. If it is against the local statutes to store the petroleum within the precincts of the town, it must be delivered either in tubs or in barrels. Provision may be made in the contract for 
the regular return of such tins, tubs, or barrels, and allowance given for them in the bills. Or such barrels may be bought outright, and used over and over again. Usually, however, oil merchants charge for the hire of the tins, and deduct the price of the hire if they are returned uninjured. It is the duty of the foremen to see that they are carefully handled. The amount of oil required per day should be supplied only on the written voucher signed by the head of the department organising the campaign. The vouchers should be returned with the monthly accounts, and they serve as a check on the bills. The foremen should give a receipt every day to the oil purveyor, stating that the amount received is as ordered, and that its condition is satisfactory-for sometimes it is so mixed with water by the middleman that it is useless as a mosquito larvicide. The oilrefined and crude-may be supplied already mixed by the purveyor, or it may be mixed by the men of the brigades as convenient or cheapest. In some countries the percentage of refined oil to crude oil is found, by experiment as to its larvicide properties, to vary considerably according to the temperature and humidity of the air; then allowance must be made. If the oil is too thin, more crude petroleum must be added; or if too thick to spread evenly, more refined oil than equal parts will be required.

Each mosquito brigade will need an oil-barrel fitted to a pair of wheels with hand shafts so that it may be pushed through the streets; horse transport is an unnecessary expense. The barrel, which may 
be made of iron, as it is more durable than wood, should be capable of holding sufficient oil for the consumption of each brigade per day. It should have a hole at the top and a brass tap at one end. Each workman should be given a bucket and a tin one-litre measure; and he should be supplied with a bundle of cotton-waste and a broomstick. The foreman's equipment consists of a notebook and pencil. $\mathrm{He}$ can be given a distinctive uniform if it is thought desirable.

With these preliminaries accomplished all is ready for a start, which need not be delayed. If there is a large ignorant population in the town, the first brigade should be instructed to begin operations in the residential district occupied by Europeans. If it is successful there, the natives will soon begin to ask for an extension to their quarter also. But there should be no delay after the preliminaries are settled and the work has been well advertised.

When actually starting the campaign the foremen and workmen should be shown mosquito larvæ and pupæ in a glass of water, and the experiment of dropping oil on to its surface repeated before them. Then empty some of the water on to the ground and let them watch the mosquito larvæ die as the water dries. This is to teach them the nature of their work. 


\section{CHAPTER VII}

\section{THE START}

ONE Monday morning should be chosen, and the foreman ordered to take his brigade of men and his oil-cart to a corner of that quarter of the town decided upon. It should be done quietly, or a crowd will be collected as a result of the advertisement. He must take with him a copy of the survey map or a sketch of the quarter in which he works, and on which the houses are divided up into equal portions for each day. He must place the oil-cart in a shady place in the street or avenue where the work is to be started.

Taking one man with him and a bucketful of oil, he enters the garden of the first house, and asks the servant if there are many mosquitos in the house. The servant goes in search of the mistress of the establishment, who appears and demands the reason of the visit. The foreman must explain his presence. If the work has been properly advertised the mistress or master of the house will be pleased to see him. The foreman must say that he has come to look for and to destroy mosquitos. If the people of the town have been already warned of this visit, their curiosity 
will overcome any opposition. The foreman then inspects the garden or compound. He must look for a fountain, and examine the water in it. If there are goldfish present he will find no mosquito larvæ there, and the fountain may be left to take care of itself. Next, he looks for some puddles of water in the garden. If there are any, he must tell the servants that such are dangerous and should be allowed to dry up. If there are mosquito larvæ in the puddles, let the workman put a few drops of oil on to the water ; or he may be directed to brush out the water with a broom. The foreman then proceeds to examine the backyard. Let him look for broken bottles, jars, or buckets containing water. These must be completely emptied out. Any washtubs containing dirty water and soapsuds must be capsized. The mistress of the house will look on with amusement, but her amusement will turn to horror when the cesspool is opened, and myriads of mosquitos fly out of it accompanied by an army of cockroaches. The cesspools of houses in compactly built towns are usually situated under or near the backyard, and there is commonly an iron lid to them that is screwed down. This must be opened. If the position of the cesspool is not accurately known, it can usually be found by examining the ventilation pipes. These pass direct from the cesspool up the side of the house. Or the soil-pipes and their position generally indicate the site of the cesspool.

The workman must be directed to pour oil into the cesspool. The surface extent of the water it 



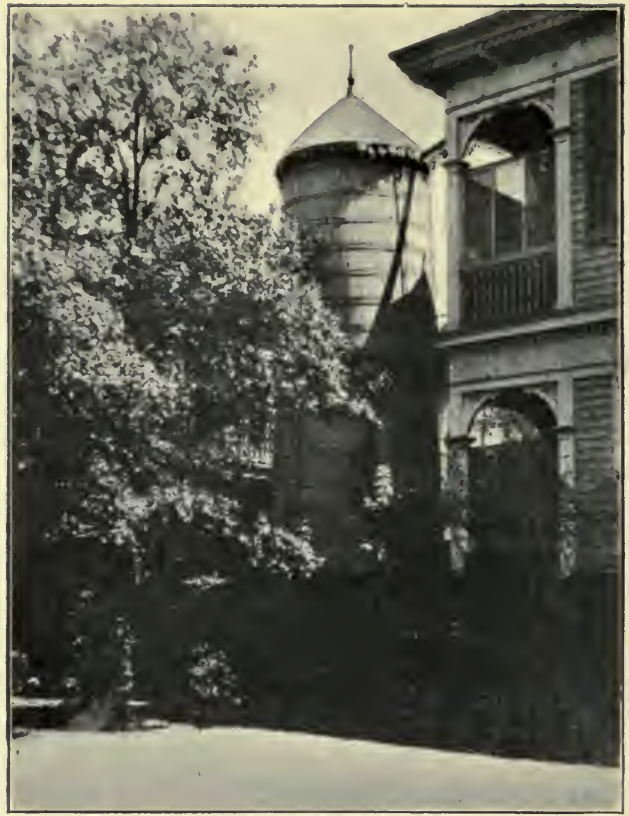

A house cistern. It is a breeding-place for domestic mosquitos.

(After Boyce.)

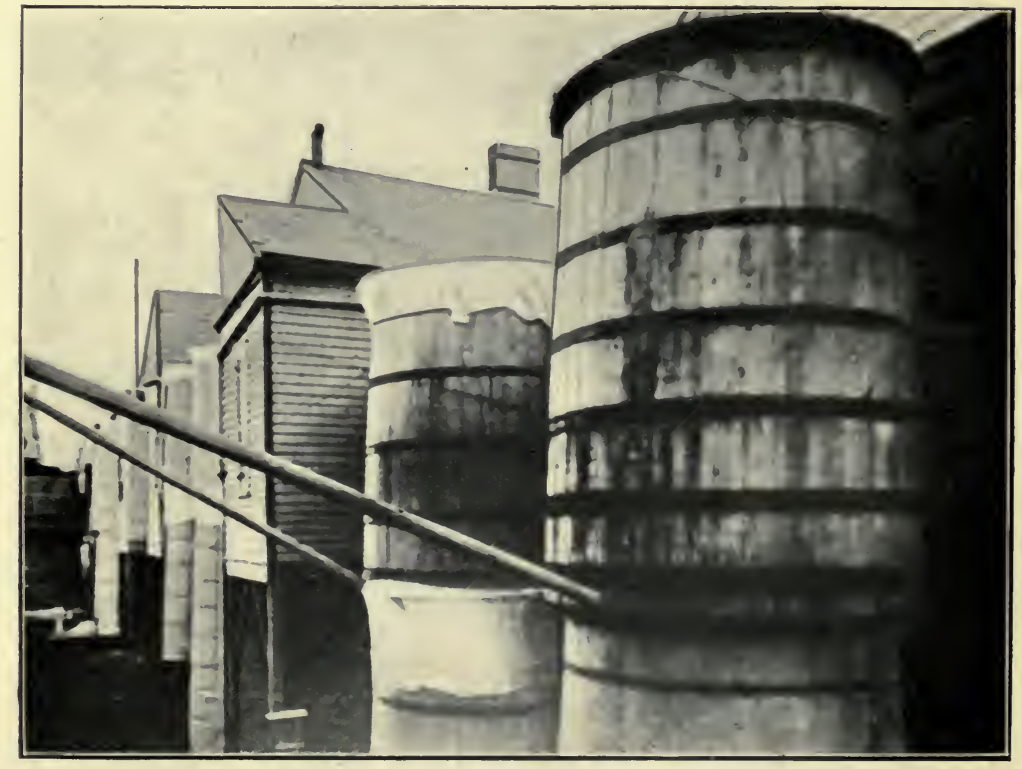

A water-butt. A breeding-place for domestic mosquitos. (After Boyce.) 
contains can generally be roughly estimated by looking through the open door. One litre of mixed oil to every square metre of water surface is the measure allowed; it need not be exact. The oil must be poured in from the litre measure, and then the water in the cesspool well stirred with the broomstick to ensure that the oil spreads evenly. If the cesspool cannot be found, but is known to exist, some oil should be poured into each water-closet and sink. This will pass with the seal-water into the cesspool, and spread over its surface; but this method is not so efficacious as actually opening the cesspool itself. The householder should then be invited to see that all water collections in the house are emptied on that day every week regularly. All flower vases, jugs, basins, buckets, saucers, or anything that contains water must be dried out.

If the water cisterns on the roof are exposed to the hot sun, or if they contain only filtered water, there will be no mosquito larvæ in them probably, and they may then be ignored. But if these conditions are not present, and mosquitos are found breeding in house cisterns or water tanks, it is better to cover them with a fine-mesh galvanised-iron wire net. In some towns the only mosquitos found breeding in such cisterns are the harmless Theobaldia spathipalpis, which do not suck blood. (This observation applies to the Mediterranean littoral only.) Turn on the water in the bathroom and see if any mosquito larvæ or pupæ are in it, and act accordingly. Lastly, warn the householder to look out for dirty water in the 
kitchen, and to have it emptied out every Monday morning by the time the brigade arrives. There should be an axiom published broadcast in the town : "No Stagnant Water."

The foreman then returns to the street, and he writes the name of the street, the number or name of the house, the name of the householder, the total water collections, the places where he found mosquito larvæ, the amount of oil used, and lastly the name of the workman that accompanied him. This house must always be appropriated to the same workman, and he must be responsible for the mosquitos, or their absence, in it. If necessary, the workman's name can be written on the wall of the house so that there can be no mistake.

The workman is then directed to refill his bucket from the oil-cart in the street, and to repeat the same process in the next house. In the meantime, the foreman takes another workman into another house and instructs him like the first, and so on. It does not take a long time to teach the workmen. At the beginning work will be slow ; for the first two or three weeks the men will not be able to accomplish all the houses allotted to the brigade on the map. But as the house-to-house visit becomes familiar, every house in the district apportioned to each brigade will be visited seriatim every week. The ultimate object is that every house in the town as well as the gardens will be visited by the same workman at the same hour of the same day every week. In this way the tenants will know when to expect the brigade, and they can 
then complain to the foremen if the work is not carried out regularly or properly.

As soon as one brigade is in full working order another may be organised, and so on until the whole town is visited regularly. The foremen should report to their chief once every day, and inform him where they find mosquitos, or if any difficulties have been encountered. They can also bring samples of mosquito larvæ found, and the insects may be classified. But their time will be fully occupied at the outset in finding out the breeding-places of mosquitos, and they must be urged to do their work thoroughly. Both the foremen and workmen are liable to become lazy after a time, for their work is monotonous; native workmen require constant exhortation. As time goes on, however, and the men learn their work thoroughly, their duties will become lighter. They will soon learn where the common breeding-places are, and find out the geography of each house and its compound. At the present time, at Port Said each brigade deals with nearly 6,000 houses every week; but many of these are houses or huts or small shops that require but little supervision.

Suppose a householder refuses admission to a workman, giving some lame excuse for his action. The workman must immediately, report the fact to the foreman. The foreman should then go and speak to the householder and try to persuade him. If this fails, let the brigade leave the house alone for a week. No attempt must be made to force an entrance. Police interference must be avoided always. Leave 
the house to take care of its own mosquitos for a time. The wayward householder will-soon change his attitude. Mosquitos will continue to worry him and his children, and then his neighbours will complain. This will soon bring him to his senses. Householders will sometimes bring forward the most extraordinary excuses to justify their action in refusing admission to the moustiquiers and the workmen into the backyards of their houses. It is because they are frightened at the visit of the sanitary authority, and fear pains and penalties at the hands of the law. One man objected at Port Said because he preferred the bites of mosquitos to the smell of petroleum once a week ; he owned a most insanitary fried-fish shop. Another said that he liked mosquitos; the pleasant buzzing noise the insects make amused his children-they were always ill, and had plenty of opportunities of listening to the music. The man's house was flooded with sewage, and he did not want to go to the expense of emptying his cellars and cesspool, which had burst. A third said that mosquitos were put into the world by the Deity to punish recalcitrant human beings, and that it would be a sin to try to reduce them; he was a very devout man until his next attack of fever, when his devotion suddenly disappeared. A native said that the British official was poisoning the water in his cesspool-perfidious Albion again!

It is better to leave such people alone until they realise the stupidity of their action. If they remain obdurate, a little tact, as will be described later, will generally overcome their prejudices. Complaints will 
arise that the workmen drop black oil about the houses, or on the premises ; they must be exhorted to be careful of such complaints. Or the lids of the cesspools may not have been properly screwed down, or the servants have been insulted, etc.; there are frequently such grievances when the campaign first starts. Such complaints must be inquired into, and the foremen should be held responsible. But such opposition wears off as the men learn their work and the mosquitos disappear. In laundries the masters sometimes grumble at the tubs being emptied. The soapy water is used over and over again, and if they are emptied out when most required, it gives extra trouble. Arrangements must be made to suit the convenience of such trades, and the masters can be asked to dry out their tubs on Saturday nights, when the work of the laundry is finished for the week. These difficulties can always be overcome by a little patience. Discretion must be employed. There is no need to pour oil into tanners' vats, for example; nor to empty wine and vinegar jars; nor to oil gas-engine circulating cisterns-the water in them is too hot for mosquito larvæ, and the oil is liable to choke the engine.

If there is a large separate native location it should not be neglected. But in some countries the natives may give trouble. This is often due to political agitation. Sanitary measures among natives in India, Egypt, and in other countries have given, and may again give, rise to riots. The best way to avoid this is to copy the methods employed on the Suez Canal. 
At Port Said, when plague broke out in 1900, some small " incidents" occurred when the Sanitary Department began soaking the houses of the native quarter in a solution of perchloride of mercury. I think the natives were to be sympathised with, for these measures did no good, cost a great deal, and entailed much discomfort. The natives also objected to the plague subjects being forcibly segregated in whole families. They became troublesome, and the police were obliged to interfere to protect the doctors. Thus people were frightened at the name of sanitation. Consequently, when the anti-mosquito campaign was suggested, they feared a repetition of the trouble, and an outcry arose. It was easily overcome, however, by confining the work of the first brigade to the houses of the better-educated European residents. The mosquitos disappeared from these houses, notwithstanding the close proximity of the native quarter, which is only separated from the European part of the town by the width of one street, and then the natives themselves began to complain: "Why are we left out? Is this the British occupation of Egypt?" Six years before they had thrown boiling oil over the doctors' heads.

The answer was simple. Another brigade was at once organised and the native quarter was cleared of its mosquitos too, the natives themselves assisting in the work. Now Port Said is wholly under antimosquito rule-native and European quarters alike.

The work will soon begin to be talked about; this should be encouraged. Let everybody know of it, so 
that the townsfolk can discuss it on its merits. The mosquito brigades are entering every house in the town at the same hour of the same day every week. They are examining regularly all shops and houses, inspecting the cesspools, wash-houses, factories, water-closets, basements, gardens, compounds, tanneries, triperies, slaughter-houses, and are dealing with insanitary places as they find them. What better sanitary organisation can there be than this ? The health officer, or the municipal council, or administration, whatever it may be, is receiving regular reports concerning the condition of the town. It is, then, prepared to deal with disease-producing centres ; it is now in a position to know of them-before it was not. The time is ripe for progress. 


\section{CHAPTER VIII}

PROGRESS

The moustiquiers, or foremen, will soon begin to report that they are finding mosquitos breeding in peculiar places, and that they are puzzled to know how to deal with them. Perhaps one has discovered that a certain house is mosquito-infested because the cesspool has burst, and the sewage is leaking out and has swamped the cellars of that and neighbouring houses. He has discovered that it is a waste of oil to deal with this large expanse of water, but that the mosquitos are breeding there in myriads. If there is any sanitary law in the land this state of affairs should be easily remedied. But in many countries where mosquitos abound there is little sanitary law, or if there is any, it is so drawn up that it cannot be enforced.

The landlord should be approached. If he can be persuaded to repair the cesspool, all well and good. If he refuses he must be forced to do so. But suppose, as in Egypt, there is no law to force him. Then he must be talked to seriously. If this has no effect, deal with him "tactfully," as the diplomatists describe it. Induce his tenants to write to him and 
complain of the smell, to threaten to leave his premises; and give them a certificate saying the place is insanitary. The immediate result will be that the landlord will refuse admission to the mosquito brigade. Then the neighbours will complain of mosquitos. If this is unfruitful of results, it is best to approach his employer-if he has one. There is certain to be some one in the town with whom he is intimately connected. Perhaps the landlord is a clerk in a shipping office. Interview the head of the firm and ask him to admonish his refractory employé. The cesspool will be repaired rapidly. A Maltese ship-chandler had a most insanitary house which he had let in flats. The tenants were always ill with fever. He was careful to live elsewhere himself. The Health Department remonstrated, cajoled, implored, without avail. He said that the Maltese were a down-trodden race persecuted by England, and he would not do anything. Suddenly a ship came into port, and the captain refused his goods, taking those of his rival. This was repeated. He complained of unfairness to the shipping agent, and was informed that "We are not so unfair to you as you are to your sick tenants." The result was that the house was repaired, cleaned, and partly rebuilt. There were several other instances of a similar nature. A clerk in a French company let part of his house to a poor family, all of whom suffered from the results of insanitation. He had repeatedly refused admission to the mosquito brigade, and domestic mosquitos continued to breed in the wash-tubs on the roof. We 
applied to the director of the company. The next time the clerk was ill and obliged to absent himself from the office he was informed that the company disliked sick employés, and it would be to his advantage if he put his house in order. The mosquito brigade was at once sent for by the clerk. M. Leonidas was a Greek, a great man, for he was a Consul. He owned the only meat market in the town. This meat market was in a foul state, for the basement was flooded with sewage to a depth of four feet. He refused to make repairs and could not be forced to do so-he was a Consul. Eventually he was constrained to rebuild the meat market in consequence of representations to the Government which he represented ; for the tenants of the market joined together and approached the Ambassador.

But it is rare that the needs of public health require such lengths of diplomacy. In the majority of instances a little persuasion will accomplish all that is wanted provided that the landlords have the means. A native, named Mohammed, came to the office and salaamed. He said, in high-flown Arabic, that the foreman of the mosquito brigade had asked him to fill up a well which he had sunk in the floor of his house; he could not afford to make a proper cesspool. In consequence the whole of the basement of the house was flooded with sewage. He was willing to fill up this well, but he could not afford to pay for the cartage of sand from the seashore to the house, and a great deal of sand would be required. A telephone message to the superintendent of police 
showed that Mohammed was indeed a very poor man, and had a large family to support. His house was rat-infested, and one of his sons had died of plague the year before. Therefore the necessary sand was conveyed to his door at the expense of the mosquito fund, and then he and his family borrowed shovels and filled up the cellars. There has been no plague there since, and his mosquitos have disappeared.

The moustiquiers will also discover many other sanitary defects in the town of a similar nature to these. Their regular visit will disclose many matters that will astonish the sanitary inspectors. They will report the presence of laundries and wash-houses, clothes-ironing shops, bakeries, skin-curing depots, leaking and unsafe steam engines and boilers, cafés and dirty restaurants, and many other insanitary trade depots that exist unknown to the town council or ever licensed by it. Such must be dealt with gently, and the owners invited to put their establishments in order. Choked rain-water gutters and eaves, drains, and old sewers will be found. Blocked canalends and pools of stagnant water will be discovered in the most unlikely places; and wells sunk into the subsoil water to save the water-rate will also be unearthed. Holes in trees containing rain-water, garden irrigation reservoirs, railway borrow-pits, infiltration water collections, ornamental ponds, steamlaunch water tanks, barge bilge-water, and many other mosquito-breeding foci will have to be dealt with each on its own merits. The foremen and the workmen will soon find them out and report on their 
existence. These seldom give rise to difficulty, and only require a dogged perseverance in discovering and dealing with them.

But sooner or later some one will become offended. Perhaps a landlord has been unduly irritated because the mosquito brigade has discovered some insanitary condition in his house that the tenants have also discovered, and they are grumbling; perhaps he has been obliged to spend more money on repairs than he anticipated in his annual estimate of pecuniary dividend. He has resented this, and seeks revenge. He may spread reports about that the mosquito work is a fad, is unsuccessful because there are still mosquitos in the town, that all the tenants still have fever, that "it's all nonsense" and a waste of money. He may write to the newspaper, or bring up a resolution at the local council board. Let him; for if the work has been begun and carried out properly, he will find himself in the minority-he will be laughed at. That is all the thanks he will get for his pains. If others are satisfied, well and good; and they will be satisfied if sincere attempts have been made to get rid of mosquitos. Every one will know that the man is a landlord with a grievance, and will regard him accordingly.

Accusations of theft against the foremen and the workmen may be made. These must be inquired into carefully and impartially. Petty pilfering is quite possible, for they have the opportunities for doing it. Examine each case. If there is reason to believe that the charge is sound, punish accordingly. 
The foremen may be discharged at a month's notice, and the workmen are on daily wages. But do not punish unjustly, or good men will be difficult to obtain. If there is a clear case, make an example and be firm.

Should a district be cleared of mosquitos, and then the insects return suddenly, the foreman should be made to inspect the neighbourhood carefully. If he finds larvæ in a place that should have been dealt with by one of the workmen in his weekly visit, and the man has neglected to do so, he should be warned. The workman's name is on the door of the house and in the foreman's notebook, and he must be held responsible. If the mosquitos recur a second time the workman's pay may be stopped for a day or two, and if the offence is repeated he may be discharged.

Sometimes a foreman will report that in a certain house mosquitos persist in great numbers, and that he cannot find the larvæ. In this case make the whole brigade search in the garden and on the premises until the larvæ are found. If they are in large numbers in one house, and by examining the mosquito curtains in the bedrooms many male as well as female mosquitos are found there, then it is certain that the breeding-place is not very far off. Examine the basement and the cesspools. Perhaps there is a buried cesspool or an unused water-closet, and the mosquitos are laying their eggs in the sealwater. If the search is thorough, the larvæ are sure to be found.

Should mosquitos return in a district that has 
already been cleared, and the foreman reports that he cannot find their breeding-place, insist that the brigade works after working hours, or on the following Sunday, until the larvæ are found; this will make them more careful. If this is done, the mosquito breeding-place is always forthcoming. Complaints may arise that a house has not been visited by the brigade for a month, and that the foreman has been seen idling away his time in a café. Find out if the accusation is correct. A few inquiries will soon settle the matter. If correct, punish heavily, and the offence will not be repeated. Make the men work overtime, or cut their pay. But one must be fair and just-then the men will work well.

It may be found that mosquitos are breeding in places that are difficult to deal with on account of the expense. Such places are large borrow-pits, infiltration water collections, birkets, urban marshes. As already pointed out, the drainage or the reclaiming of such places really comes under the heading of major sanitary works, and should have been noted as such when making the estimate of the cost. Such major sanitary works should be undertaken by the municipality or town council as its duty; it should not be left to the enterprise of some individual department - certainly not put to the account of a mosquito campaign. The reclaiming of a ditch in the centre of a town should not be charged to the credit of the Health Department merely because it is insanitary or because it smells. These are general municipal measures. Frequently one sees such matters forgotten. 



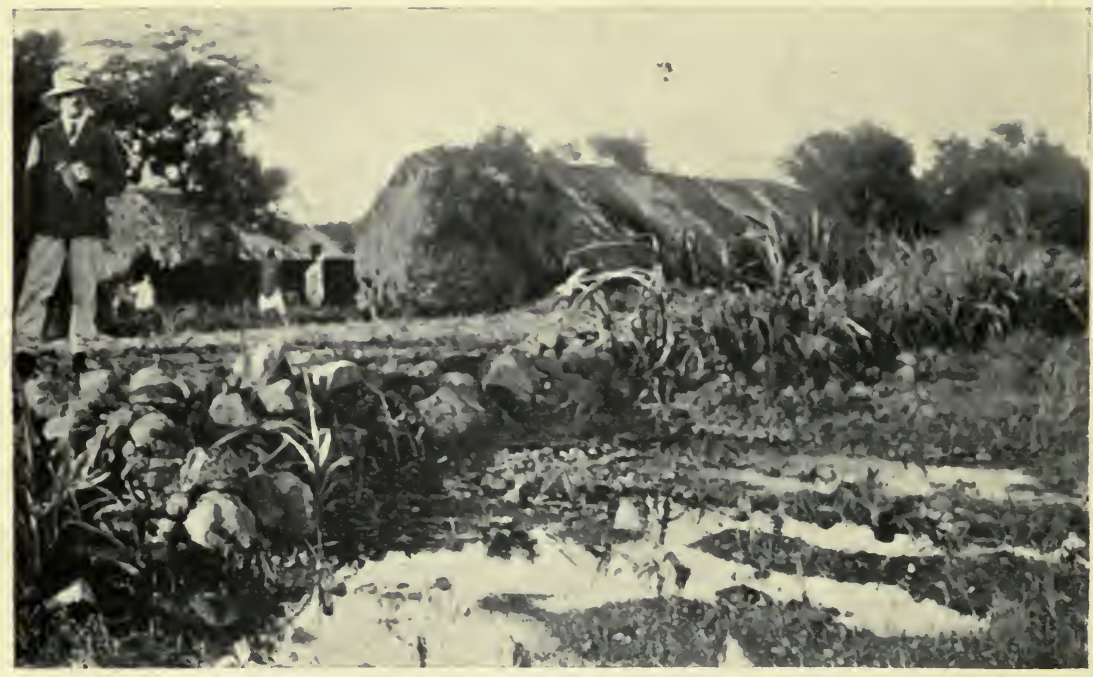

$\Lambda$ borrow-pit in which domestic mosquitos breed.

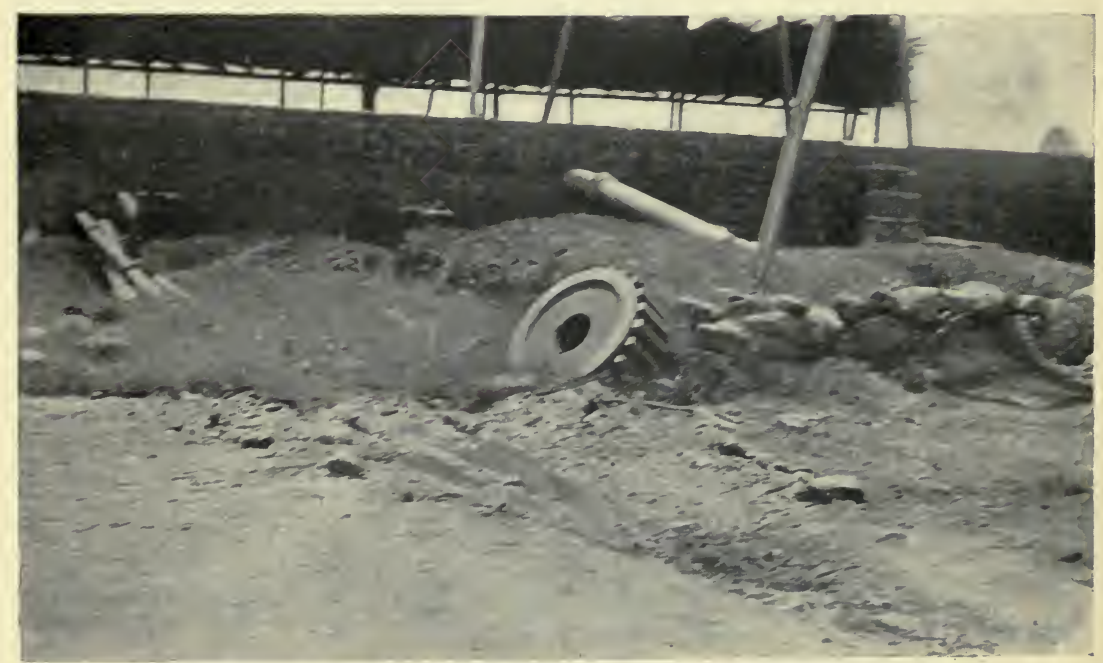

A sewage-flooded backyard breeding domestic mosquitos.

[p. 85 
I have witnessed a Government pass a proposal for an expensive pier or an opera house, disregarding the fact that the death-rate in the town was 40 per 1,000 .

The filling up of borrow-pits and infiltration water collections is often an expensive matter. In Egypt, the cultivated area is restricted to the valley and the delta of the Nile. And as there is no impermeable stratum of soil, the height of the subsoil water varies with the level of the river. Fvery autumn the level of the Nile rises owing to the flood produced by the monsoon rains in Equatorial Africa, and consequently the level of the subsoil water rises too. There are throughout Egypt, in the cultivated area and in the towns, many natural and artificial hollows and depressions in the land surface, called birkets. When the Nile has reached a sufficient height the subsoil water infiltrates from beneath, and the birkets become pools of fresh water. The numbers of these pools and their extent varies with the maximum height of the river at its annual flood, but the water often remains in them for some weeks after the river has begun to fall again. These pools are suitable breeding-places for all species of mosquitos indigenous to Egypt, and the insects swarm. In the towns and villages these birkets become open cesspools, and the smell from them is terrible. In Cairo, during the annual flood, the Nile water wells up into the basements and cellars, and bursts the cesspools, and the whole town is converted into one large sewage swamp in the high-flood years-the years of 
the "fat kine." At Port Said, the sea water is only one metre below the road levèl, and there too the basements were flooded frequently with a mixture of sewage from the burst cesspools and subsoil water. Such basements were filled up with sand from the seashore by the landlords, who were persuaded to do it at their own expense; but the sand was free, and the carriage cheap. In Cairo, on the other hand, the birkets are for the most part owned by the Government, and nothing would induce the Administration to spend money for the purpose of reclaiming its own property. In Cairo, the filling-up process, so urgently desired, is an expensive operation. The common price charged there by local contractors is 1s. $2 d$. per cubic metre, including the cost of material, and great care must be exercised, or new birkets will be formed by the borrow-pits made slyly by the contractors-the earth must be obtained from somewhere, as street sweepings are inadmissible from a health standpoint. Such examples as these are set down here in order to show that major sanitary works are invariably expensive, and that the reclaiming of swamps in the middle of large towns may cost much money, even when the water comes from below, instead of from above as rain.

In Port Said we had to face another difficulty. Our foremen were obliged to understand and to speak six different languages. The town contains the riffraff of all the nations of Europe as well as native Egyptians, Syrians, Indians, and others, including Arabs and Bedawins. All these people are under the 
control of their own consuls only, and the sanitary authority had no power. Each colony is self-contained, and will brook no interference from officials of the Egyptian Government. The consuls were often haughty personages of their respective diplomatic corps, and it was frequently found a hopeless undertaking to appeal to them for help, though some of them assisted in every way. We were forced to employ every ingenuity to gain our object-public health. It is to be hoped that others will not meet with these unnecessary difficulties, but they are set down here from the store-book of experience so that he who runs may read, overcome, or steer clear of them. Perhaps in the place of the difficulties encountered in Egypt others will arise elsewhere, and they will have to be surmounted in a like manner; they can be surmounted, that is the chief thing. If there are laws that will assist in the prohibition of stagnant water, they may be enforced if necessary. But where persuasion will obtain the same result, it should be employed for preference. Popular administration does more for the community than despotism, and it is more lasting. 


\section{CHAPTER IX}

\section{MOSQUITO REDUCTION}

The mosquito at last had drunk her fill. She had been born three days before in a neighbouring cesspool. The water there was warm, and her larval life, from egg to perfect insect, had only occupied about fifteen days. On emerging from the water she had flown about in the foul air of the cesspool for twenty-four hours, and had fed on the floating excrement. Then she had consorted with a male of her species-one that had probably arisen from the same egg-raft as herself; he was in fact her brother. Her spermathecae were, in consequence, full of spermatozoa, and this had made her crave for a more strengthening diet than anything the cesspool could give her. For hours she had striven to find an exit from that environment without success. But at length she had found her way with a swarm of others through some chink into the adjoining cellar, and had flown up the stone stairs to the kitchen on the ground floor. It was the evening when she emerged into the society of human beings, and the air was still and the heat overpowering. The long flight had been accomplished by easy stages, for she was famished for blood, and had been obliged to rest in dark corners. 
She had flown to some clothes that were hanging behind the door and had rested again.

After a short time hunger again manifested itself, so she tried to clean her proboscis with her forelegs, but it only made them sticky and uncomfortable. She then tried to thrust the end of the proboscis into the cloth, but this was only partially successful, and the cotton hurt her bristles. She flew out of the kitchen, which was deserted, for the native servants were cackling to each other on the stoep, and she at length had found her way into a bedroom where there was a man lying ill on a bed. He had pushed the mosquito net aside to get more air, and then had fallen asleep. The room was almost dark. She settled at once on the mosquito net, waving her hindlegs in an expectant way. The thoughts of a meal made her feel a pleasurable excitement, but she also felt, instinctively, the need for caution.

The man's hand lay exposed on the coverlet, so she hopped down and alighted very softly on to the back of his fingers. Again she rubbed her proboscis, and then very gently attempted to thrust it through the skin, which was hot and pungent with fever; the sleeper was sweating profusely. But the skin here was hard, and she could not pierce it. She changed her position slightly and tried another spot, where at the bottom of a tiny fold between the palm and the little finger she could gain an entrance. Immediately the point of her proboscis entered the cuticle her saliva began to flow into the skin, and before she could pierce any small vein the sleeper moved his 
hand. But she was ready for this, and quickly flew up to the gathered mosquito curtain above. Soon all was quiet, and after a moment's rest she again determined to venture for her food. She moved down gently as before and attacked the man's lip. Here she obtained a few minute drops of blood, but again the sleeper moved, and she was obliged once more to seek her refuge.

The frugal meal she had obtained had only whetted her appetite for more, and a third time she returned to satisfy her lust. This time she approached the sleeper's ear, but the buzzing her wings made woke him, for he suddenly sat up in bed with an oath, waved his arms about his head, and then set himself to scratching his lip. The wind and disturbance he made with his arms caused the mosquito to fly away to a far corner of the room, and contemplate with quaking thoughts the difficulties of obtaining the necessaries of life. In the meantime the sleeper pulled down his mosquito curtain and tucked it in under the mattress. She tried again to approach him, but he had hidden himself behind an impregnable fortress of muslin. So she stood on the perpendicular part of the curtain and waited as the evening closed in.

Suddenly a bat flew in through the open window, and swooped about the room, attracted by the small midges that were disporting themselves in a shaft of light thrown by a street lamp outside. The bat did not see her, but its presence terrified her as its wings flapped past the mosquito net. 
At last her hopes of renewing her meal were again raised when the bedroom door opened and a native servant entered carrying a tray. She at once settled on his clothes near his bare neck, and was carried by him into the passage of the house. He moved so quickly, however, that she was obliged to leave him, and entered the open door of another room. Here there was a child asleep in a cot which was covered by a long mosquito curtain. On this she alighted, and again waited. Presently the infant's arm was thrust against the net, and then she was able to satisfy her appetite from its blood. But on this occasion the child moved, and she took refuge under the bed, as she realised that this was the safest place from her natural enemies. When on the child's net she noticed that there were a score or so of mosquitos like herself, with their bodies distended with blood. But there were only two males among them, and they both belonged to an alien species, and they had not fed on the child. What had become of the swarms of males that she had left in the cesspool? She wondered why it was only her sex that required blood. Why had she to risk her life for food while her husband and brothers remained contentedly in their home, the cesspool ? But she had had a good meal at last, and it was making her drowsy. Her body was distended, and it sagged downwards with its weight; this tired her legs, so she crawled up the net to a place where a fold made it more horizontal, and she could get a hold with her claws; then she slept. 
That night and all the next day she slept and digested her meal. In the evering she felt hungry again, but it was early and the child had not returned. Therefore she flew out of the open window and distended herself from the black skin of a native who was sleeping in the backyard; his ankles supplied her wants readily. The next night the baby in the cot satisfied her through his mosquito net, which was badly tucked in under the mattress; and again she noticed the absence of her brethren, but noted that the numbers of her sisters on the net had increasedsomebody had opened the cesspool and they had flown out in search of blood. Four nights later she had her revenge on the sleeper in the front room, for he was tossing about in the semi-delirium of fever. She gorged herself, and was satisfied enough to sleep for hours after. She rested every day and fed every night until she had made the acquaintance of every member of the household, including all the servants. She even knew the geography of the house and the taste of the water on all the washhand-stands. But for the occasional bats, lizards, spiders, and a bird in the garden, her life was a peaceful one. However, as she grew older she learned to avoid such enemies by hiding, and she knew exactly how to get under the bed when a sleeper woke and tried to squash her distended body.

As time progressed the eggs within her developed, and she felt the weight of pregnancy bearing upon her. Her meals of blood had been regular and frequent, and she was ready to lay her first brood within 
a fortnight of her first meal of blood. Where should she go to lay her eggs? She had tried all the water in the house, but it was all clean and filtered; it contained no food for her young. She searched the house. If she did lay her eggs on the clean water in the jug, there would be no male for her to consort with again. She looked everywhere-no males.

At last she determined to return to the cesspool where she had been born. She knew that there would be males of her species therein, and that the water would contain plenty of food for her young larvæ when they had hatched out of the eggs. She flew down the stone stairs, through the chink in the wall of the cellar; but a new smell confronted herpetroleum. The surface of the water was covered with it. Everywhere she went the oil faced her. There were no males here. No mosquitos of any kind. What was she to do ? She could not lay her eggs on oil. So she left her birthplace and sought another water collection. Everywhere she found the work of the mosquito brigade. Utensils were either empty or contained only clean water, and all stagnant water had been recently oiled.

Eventually, after searching in every direction, she wandered to another house and found a fountain in the garden. The water contained many mosquito larvæ. There had been goldfish there, but they had died for some unknown reason, and the mosquito brigade had not noticed the fact. She laid her eggs on the still water during the night, and in the morning found a newly hatched male to fill her exhausted 
spermathecae with his spermatozoa. Then she reentered the adjoining house and started feeding again ; but she noticed how the mosquitos had almost disappeared. This was of some advantage to her, for the inmates of the house no longer used mosquito curtains and she was able to feed uninterruptedly.

Six weeks later she had another brood of eggs to lay. The fountain was now dry. She searched high and low, but there was no water anywhere that was suitable for her eggs; also there were no male mosquitos. All the cesspools contained petroleum, and even the cisterns were screened with wire gauze. So she laid her eggs in some clean water in a basin, but the larvæ died for want of food. She searched for a male mosquito of her species to consort with again ; he could not be found. There were no mosquitos at all. Then the craving for blood seemed to forsake her. She became a vegetarian, living on the juices of old banana skins and discarded watermelons. But her life, once so full of adventure, was blasted, and she died disappointed, but with the knowledge that she had lived.

Such is the tragedy of the last of the mosquitos; it is the only tragedy of a mosquito campaign if the latter is properly carried out-the remainder is comedy, and an interesting one. The mosquitos disappear rapidly. In a few weeks, even in the hot weather, there will be comparatively few insects left. After three weeks, at Port Said, many of the mosquito nets were put up for good. In parts of the town where leaky cesspools existed, mosquitos per- 



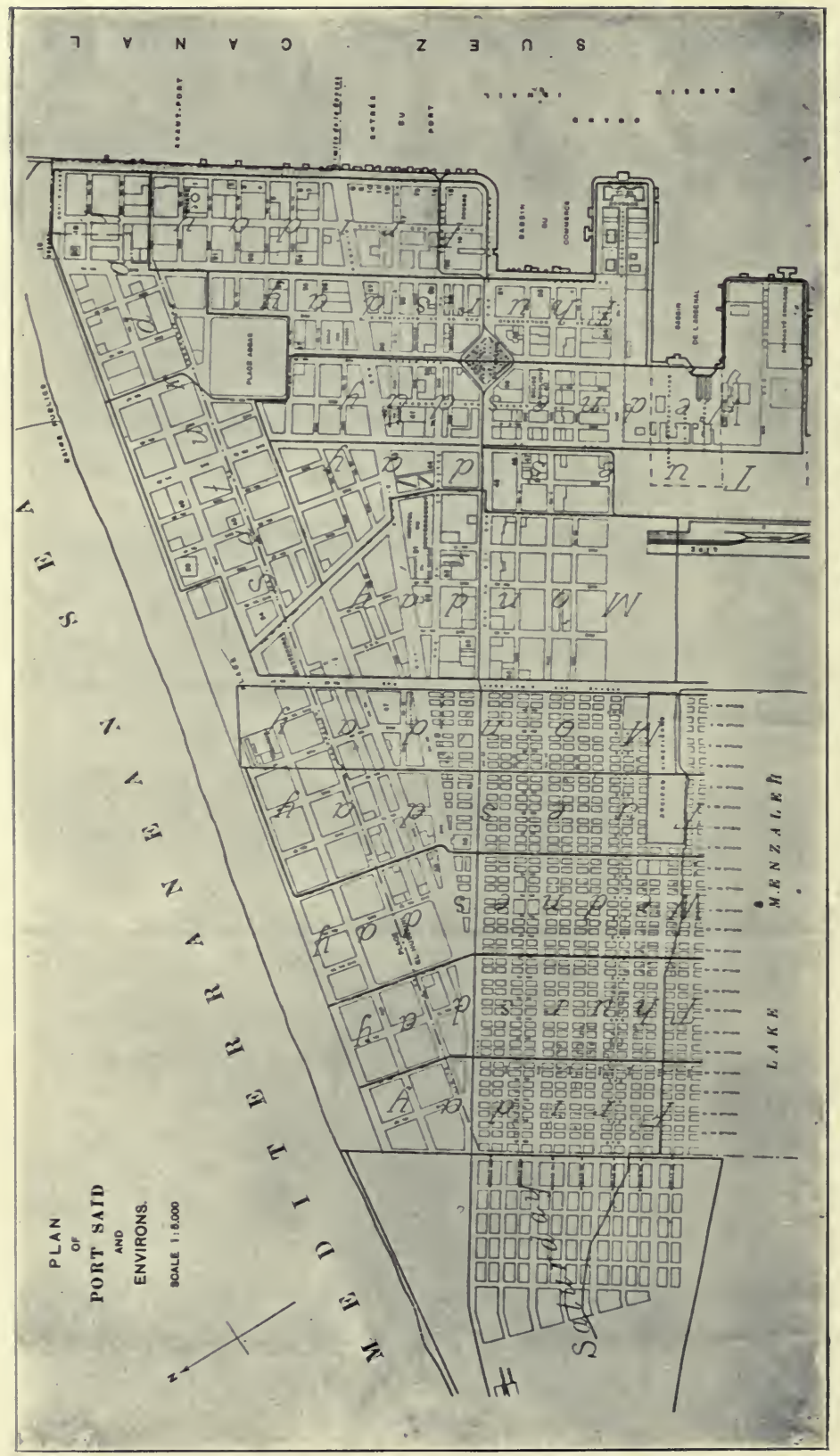

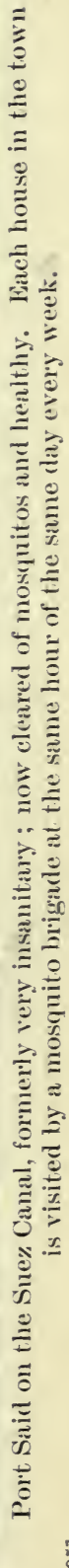


sisted or returned in one or two houses, and this happens now if the mosquito brigade stops work for a single week.

The male mosquitos are the first to be reduced. Their lives are so short that if their birth-rate is suddenly curtailed their population disappears almost at once. Then the existing females cannot effect the coitus necessary after laying a number of eggs. They also cease to annoy human beings. Any food would seem to suit these widows; they are not very particular about blood-sucking when they have no eggs to mature.

So mosquitos ceased to trouble, and with them went the fever. The unhealthy, pallid-cheeked children, the unemployed men, and the sick wife disappeared with the fever, and the misery became ameliorated. Away went most of the professional beggars, the factories began work again in the summer, and the workshops had no need to close. The attendance at the schools is now good and the children are well and strong. They have some colour in their cheeks, and are able to play on the beach-it is a very different state of affairs. The place is buzzing, docks are being constructed, shipping dues are rolling in, and trade is progressing. It has cost about $£ 1,000$ a year, or sixpence per head of population annually. 


\section{CHAPTER X}

\section{REPORTING PROGRESS}

While mosquito reduction is in progress it is interesting to watch the fever reduction. Unfortunately, there is no exact method known by which the number of mosquitos in a locality can be counted. Many attempts have been made to estimate the numbers of mosquitos in a town; all are unsatisfactory. The total number of stagnant water collections and the percentage of those infected with mosquito larvæ estimated before and after the mosquito campaign is started has often been employed as a method of reporting the results of a campaign; but the method is not exact. For example, when the first estimate is made, a house may be declared to contain no suitable water collections and to be free from mosquito larvæ. Then while the work is in progress a native servant may leave a bucket of dirty water hidden in a corner of the kitchen, and the house will become full of mosquitos (thousands of mosquitos may be produced from a single saucer of water in three weeks). This will vitiate the results at once.

There is no accurate means of counting the number of mosquitos in a house, or even in a room. 


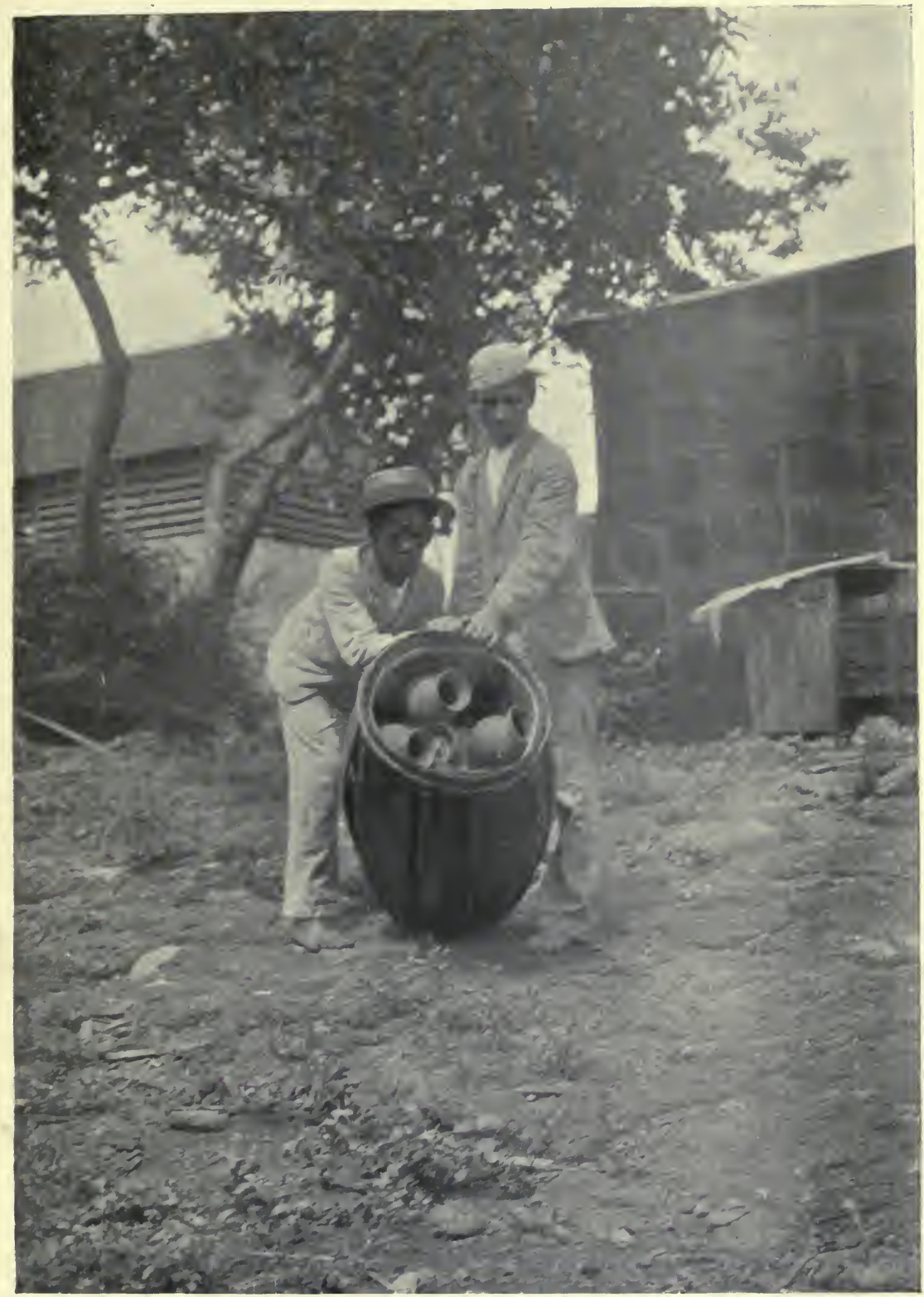

p. 96]

A favourite breeding-place for domestic mosquitos. 

Several kinds of mosquito traps have been devised, but they give little exact information. For every ten mosquitos caught in a trap there are probably hundreds that avoid capture. The writer has tried many experiments with traps, but has been obliged to give them up. There is one simple way by which a rough estimate of mosquito reduction can be obtained. It has been stated before that the first mosquitos to be reduced will be the males. Male mosquitos habitually remain for their short lives near the breeding-place where they themselves were born. Only occasionally does a male follow the females into houses; the large proportion remain near the water to fertilise the females as they emerge from the pupa. But in a room infested with female mosquitos an occasional male will find his way there to fertilise a possible virgin female that has wandered with her sisters into the house. These males can be counted before the anti-mosquito measures start, and counted again a month after. Choose several houses in scattered parts of the town, and in one of the bedrooms of each count the number of males found resting on the mosquito curtains. Note the houses and the rooms, and utilise them again for the next count. If there is a reduction of males, the work of mosquito prevention is going on well. Examine the nets in the morning. If after some weeks there are still males to be seen on the nets, it is certain that there are yet breeding-places to be dealt with. If on one mosquito curtain there are several male mosquitos, it is only necessary to find the breeding-place 
that has been overlooked by the brigade; it is probably on the premises. This method is only a rough one, and cannot be relied on to give exact information; several males may be found in one room, and not one in another, even in the same house. Domestic mosquitos do not fly far from their breeding-places, as already proved. If, however, a mosquito campaign is perseveringly conducted, the insects will be reduced so rapidly that an exact estimate of that reduction is hardly necessary.

The most satisfactory result that can be reported is the reduction in the amount of fever. The fever census should be taken periodically. Pay a visit again to all the schools. Medical examination of all schoolchildren is now a recognised routine health measure. Mosquito reduction is an excellent excuse for its institution, if such be needed. Examine a hundred scholars every day. Arrange with the schoolmasters that a hundred children be drawn up in the quadrangle or yard, or playground, or large classroom, and then send down a doctor, or, if this is impossible, an interested school visitor. Inspect the children. How many out of the hundred have anæmic, pasty faces? How many have eye disease? How many have loathsome skin diseases? How many have swollen bellies or enlarged spleens? What is the total number of scholars, and how many are now absent sick? How does this number compare with the figures obtained at the first fever census? If any of the children are "doubtfully ill," place them together on one side, and examine them more care- 



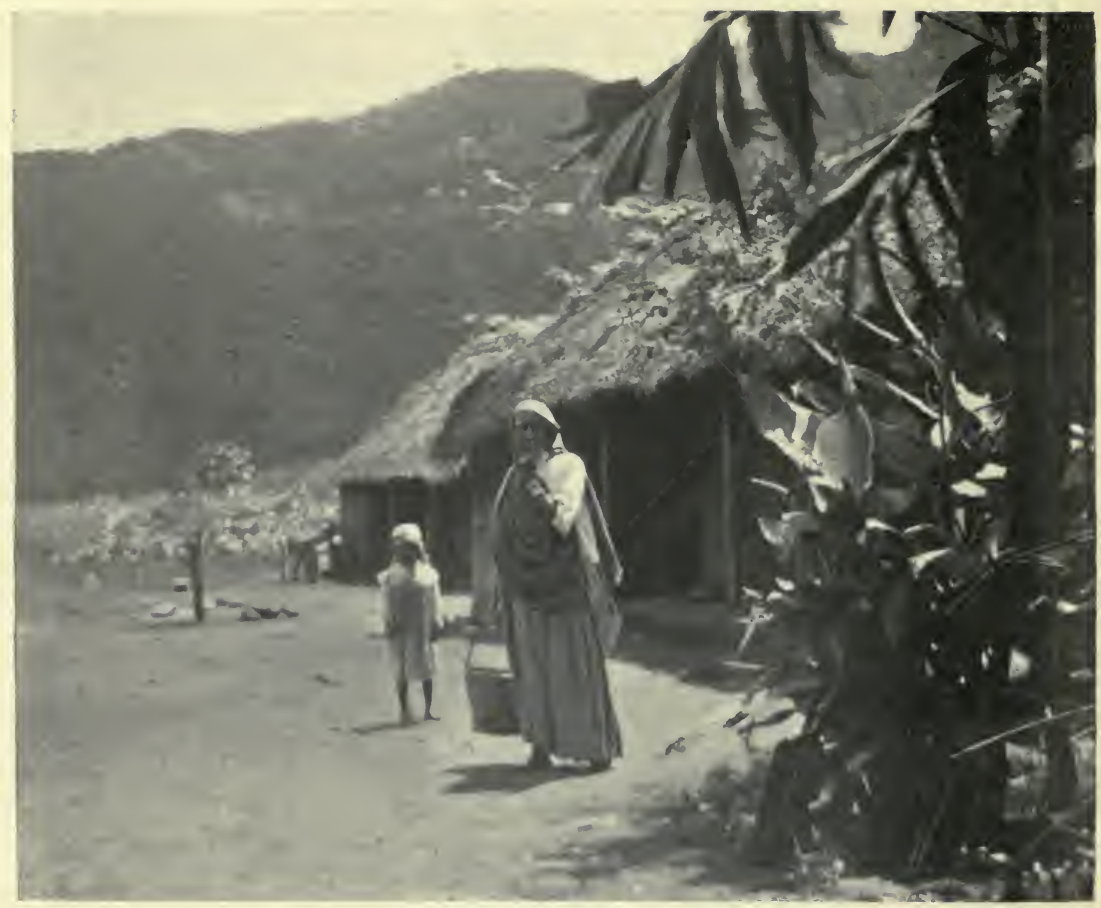

A cesspool under a native hut will produce many mosquitos and much sickness.

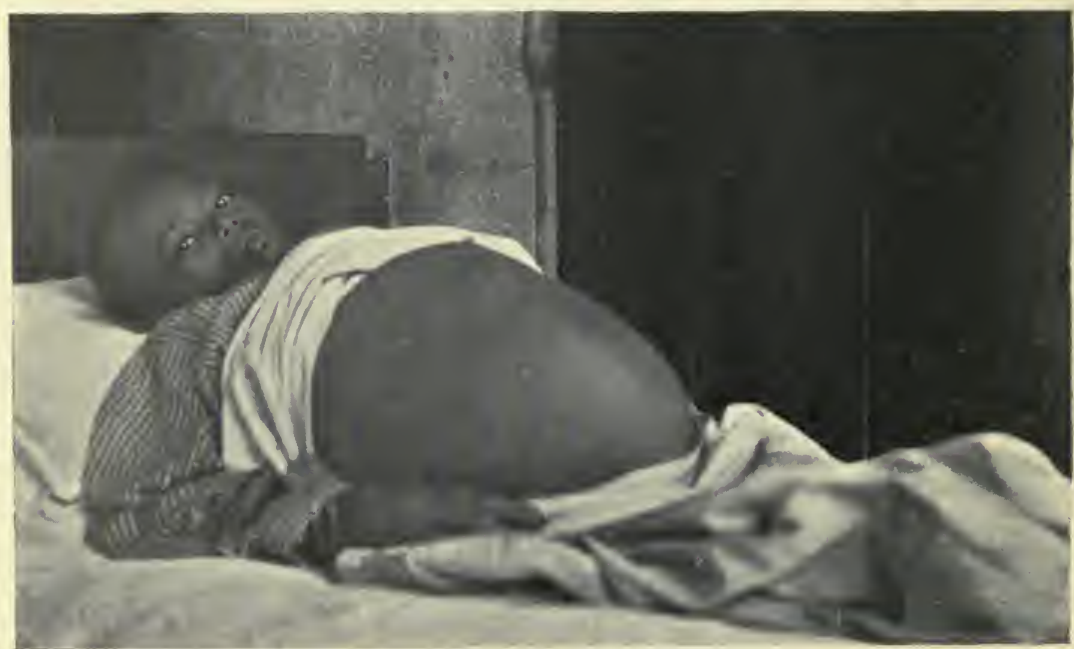

Native child with an enormously enlarged spleen from malaria. 
fully, making them lie down on a table or form. Be gentle, for if one child begins to cry all the rest will follow suit out of sympathy, and that will be the end of the examination-crying is a catching complaint. Try to find out what is the matter with the sick children. Ask them whether there is any sickness at home. If there is any fever amongst the schoolchildren, ask the master to keep a register of those who are affected, and again carefully observe the same children when making the next census. If this is done throughout the town schools, the most interesting facts will come to light. But examine the healthy as well as the sick.

It is not sufficient to inspect the European schoolchildren alone. Go into the native locations and look at the children there. Perhaps malarial spleens will be found, or "latent" yellow fever. Examine the children in their houses or in the streets, and keep a record of then. If there is malaria, a hunt for the Anophelines must at once be instituted; or if yellow fever is suspected, it must be dealt with at once by house fumigation, isolation and screening of the sick, etc.

This is the most interesting and gratifying form of public health administration; and all the time there is the knowledge that progress is being made. Inquiries may again be made of the factories, similar to when taking the first fever census. Every six months the examination of the town should be accomplished, and at the end of the year the fever census must be taken in precisely the same way as 
before, and the results compared. But there must be no " jumping" to conclusions. It is quite insufficient to examine a hundred schoolchildren and to find only two of them absent for fever, where formerly five were laid up, and then to conclude that there is a reduction in the town of three per cent. Such a conclusion is quite unjustified. There would be such a statistical error that the conclusion would be wrong. This is random sampling, and it gives erroneous impressions. Strictly speaking, all the schools in the town should be examined at least once a year, and more frequently if possible. Omit no detail, and be careful and painstaking-it will be well rewarded.

Collect all the figures available, and correlate them. The percentages must be worked out from the whole, not from individual units. Remember that "averages are numerical expressions of possibilities ; extreme values are expressions of probabilities." Also that "the value of a series of observations increases with the number of observations; the value of the deductions with the square root of that number." How frequently official reports claim the reduction of a disease in a large community because, out of a hundred in-patients treated in one hospital, ten per cent. suffered from that disease compared with fifteen per cent. the year before! Such an inference is not only unjustified, but is actually incorrect. If deductions are drawn from percentages or averages, large numbers must be employed.

An interim report should be published. It should describe the area dealt with by the mosquito mea- 
sures, the difficulties encountered, the personnel employed, the amount of oil used, and it should include a statement of accounts. The fever census returns should be quoted, but no deductions or claims of reduction of fever incidence should be made in six months, for example. A much longer time must be given before any such results can be expected in numerical form free from error, although the fever has been reduced without doubt. In the same report some of the more sanitary backslidings of the town may be described, and their remedies suggested.

In this report an important point may be emphasised. Mosquitos are a disgusting household pest. By their diminution the town is being rid of a plague. Any one who has visited the tropics will testify to the discomfort caused by the domestic mosquito. Even in subtropical countries this holds good. A visit to Venice, for example, is spoiled by the misery induced by Culex fatigans and Stegomyia calopus. In the summer, when Venice is most picturesque, these mosquitos make life unendurable; the former annoys at night, the latter all day long. The hotels are full of them, and these species attack the tourists even in gondolas on the canals; they give one no peace. All day long one is squashing the striped Stegomyiæ, and the Culices bite one's ankles during dinner; the mosquito net effectively keeps out the fresh sea breeze on hot evenings. Venice could be cleared of this pest with the expenditure of some energy and a small sum. The cesspools could easily be dealt with as at Port Said and Ismailia. Culex and Stegomyia do not 
breed in the sea water of the Adriatic; there are no larvæ in the Grand Canal. It is only a matter of simple sanitation. Venice is unhealthy during the summer months (if not all the year round), as Port Said was; and it is largely due to mosquitos. It is such a pity.

There, whether one rests in the hotel lounge or outside a café, or idles away an hour in a gondola exploring the water byways, one is incessantly scratching and grumbling, or striving to smite these irritating insects which have just risen like a miasm from a Venetian cesspool. How can the stones of Venice be appreciated under such conditions? Then the traveller returns disgusted and irritated to his hot bedroom at the hotel, and sits by the open window to enjoy the breeze and the oft-repeated, twangy Neapolitan serenade that is being "breathed" beneath him. His thoughts fly back to the Doges, and the Rule of the Ten perhaps, to Byron, or to Ruskin, only to be suddenly awakened to the hard and matterof-fact present by the bite of a Culex or the "ping " of a Stegomyia - the flight of the mosquito is quicker than his thought. At last the traveller is driven to bed, pursued by this persistent pest, and he lies there panting, sweating, and cursing under the mosquito net. Then does his sympathy go out to those Ancient Venetians who forsook their home to settle elsewhere in the Mediterranean and the Levant, where they built picturesque old cities on high walls that were surrounded by sea.

Natives and persons long resident in the tropics 
sometimes become so accustomed to inoculation with mosquito saliva that it fails to irritate them. They frequently aver that they are not bitten. But examine their mosquito nets in the morning; there will be plenty of recently fed females there. The old residents become immune to mosquito poison. Examine the arms and face of a newly born infant in a house that is mosquito-infested and look at the wheals produced by the insects; no wonder the child cries at night.

Mosquito reduction will relieve all this misery, and it will do so very quickly. Here alone is sufficient excuse for its institution and maintenance, even if it is certain that there is no fever. 


\section{CHAPTER XI}

FINANCE

The municipal cashier should be directed to keep the accounts of the mosquito credit or fund under a separate entry; otherwise all sorts of undertakings, charitable and otherwise, will cause leakage of the money. Nothing should be paid from the credit unless formally approved by the person who is directing the work. There must be a responsible head, or the funds will be diverted to other uses. As stated before, the local health officer is the best organiser for a mosquito campaign, but this is not absolutely necessary. Whoever directs operations must see that there is no " juggling" with the collected, subscribed, or granted funds. After the campaign has started, if the necessity for major sanitary works becomes apparent, and these are agreed upon, credits allowed for them should be kept separate. Then should any one of them fail, its downfall will not include the measures against mosquitos. Payment of bills, etc., and the salaries must be made regularly. Proper pay-sheets for the foremen and workmen should be employed, so that records of promotions, rates of pay, punishments, etc., may be kept. 
Perhaps during the early part of the campaign some displeased landlord, who has been forced to put his house in order, may cavil at the expenditure, hoping to undermine the cause. It is best to ignore such busybodies; but if he is powerful, and an answer is pressed for, it is ready to hand. The question of public health is one of finance. What is the value of a human life to the community ? Thirty years ago, in the old slave market at Zanzibar, it was possible to buy a negro woman-slave for twenty pounds. Her purchase, from capital, would save her master from paying her regular wages of about $£ 1$ per month, but her food cost him something. In Egypt to-day a native labourer can command £2 per month, or $£ 24$ per year. Every one of these labourers contributes towards the welfare of the State by paying taxes, either direct or indirect, by working so that the taxed imports and exports are swelled, and by contributing to the progress of the communities of the towns and villages. It is by the size and industries of these towns that the stability and progress of the State are judged. The credit which a State can command varies directly with the amount of work done in it; that is, it is dependent on its industrial output. But this industrial output varies with the number of inhabitants, and their ability to work; and their numbers and ability to work vary directly with their health. This is a platitude of political economy, but it is one that appears to be seldom realised. The question therefore is answered: The value of a human life varies directly with health; the same may 
be said of the community. England is the healthiest nation in the world and it is the richest. At Zanzibar, the cost of the least valuable of human lives used to be £20. But suppose the slave died, then the capital expended upon her was lost (for there was no insurance company to insure slaves at Zanzibar in those days), as was the work that would have been done by her. Or if she was constantly ill and unable to work, the cost to her master was even greater, for she had to be provided for during her illness ; it was increasing capital expenditure with compound interest. But if the slave's life could have been saved, or her illness avoided, then the capital expended on her would have been actually repaid by her work. All persons are slaves of the State in which they live, and for which they work, and if they are healthy they will gradually repay any capital that is expended by it on their welfare.

If the State pays sixpence per head of population per year, and thus renders the whole community free from certain diseases, or if it merely renders the life of that community more comfortable, the capital sunk to produce the sixpences ( $£ 33,000$ at 3 per cent. for a community of 50,000 ) will soon be repaid. The death-rate will fall, and healthy children will grow up instead of unhealthy ones. Every healthy child is an actual financial asset to the State, for it will do its share in increasing the industrial output. And this increasing output will improve the credit of the State. As the success of the mosquito campaign becomes established, and the insects disappear, the 



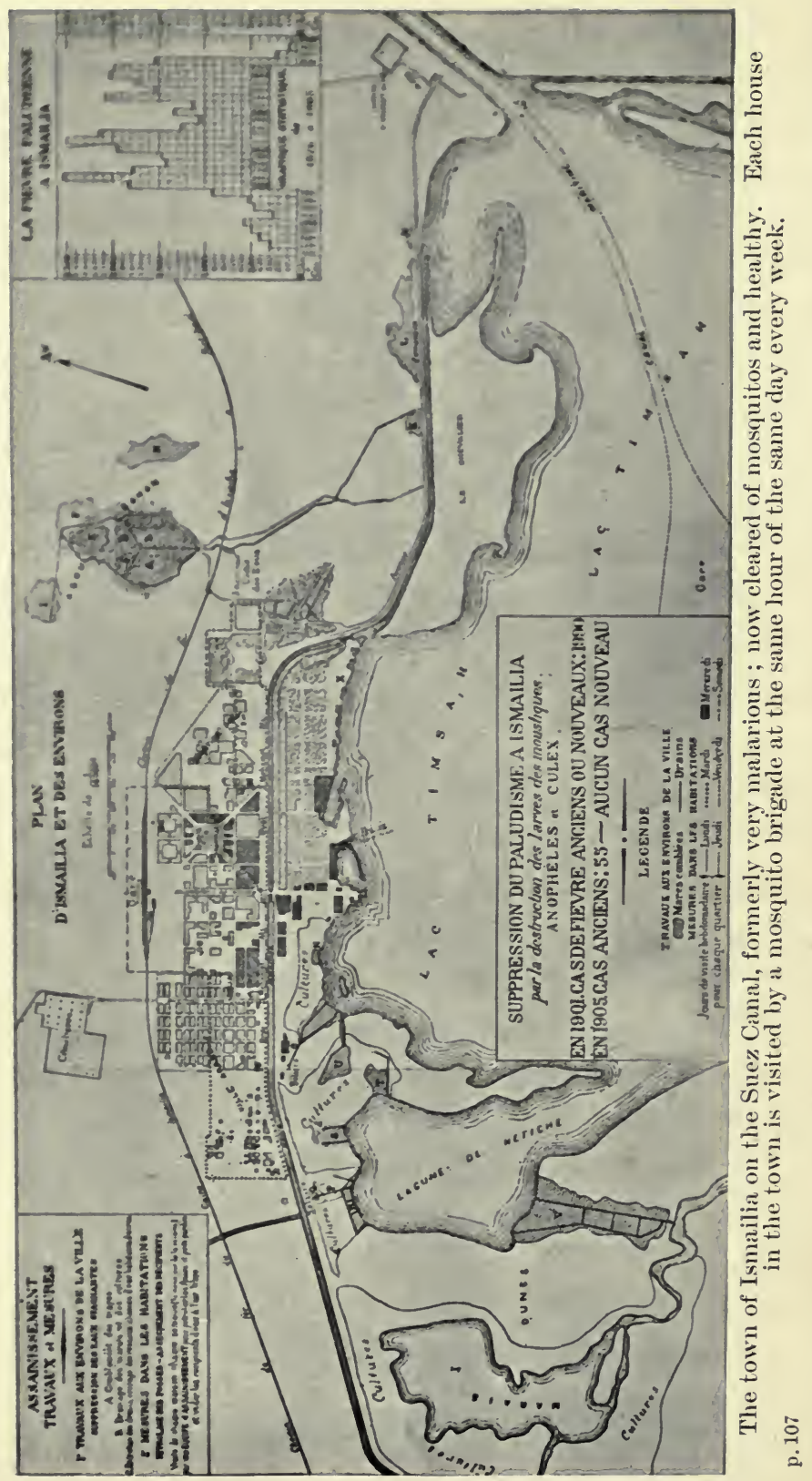


cost of the upkeep of the work will diminish. But in the meantime the town will progress, its financial position will improve, for its credit will become cheaper and greater. Ultimately its population will increase because a falling death-rate, progress, and the improving credit will attract immigration, and then the rate of sixpence per head per year will fall until perhaps a penny will be sufficient. At Port Said during the first year of the mosquito campaign 41,120 gallons of petroleum were used, but during the second year only 31,670 gallons were required. In that town, also, the campaign cost $£ 1,176$ the first year (1907), and this sum fell to $£ 1,023$ in the second year. Now (1910) the annual cost is only $£ 800$, and the population of the town is increasing rapidly. Lastly, the improving credit of the place must have repaid the capital buried more than once already. Other towns, Ismailia, Havana, Rio, New Orleans, Klang, Santos, Colon, Panama, etc., tell the same story. So if the work has been well performed, and successfully carried out and maintained, the professional grumbler will soon be gagged by the weight of public opinion.

It is as well, however, to curtail, as far as possible, all unnecessary expenditure. See that the workmen do not waste oil. One lazy man may pour all his allowance of oil into one cesspool, and then rest in a café for the remainder of the day. If he does this, the mosquitos will reappear in the neglected houses, and complaints will soon come in. As his name is written on the door of these houses, he will soon be 
discovered and can be punished. At the end of every year the amount of oil may again be put out to tender and the cheapest offer accepted ; perhaps an economy may be effected in this way. So much oil may not be required as before; the exact amount required can be estimated from the foremen's notebooks. After a time, when the mosquitos have almost completely disappeared, the staff employed may be curtailed; but this should be done cautiously. By a little foresight and thought, the area of water surface to be dealt with every week may be reduced. At Port Said, when we started, we found 400 cellars in the town flooded with sewage from leaking cesspools. These cellars were underground catacombs of sewage, having 7,296 square metres of water surface to be dealt with every week. They were therefore filled up with sand from the seashore. It was done by the landlords as described in a former chapter. Occasionally assistance was given by grants from the mosquito fund, for it was realised that a dry cellar is cheaper than constant oiling.

Then again, in rainy climates, domestic mosquitos will sometimes breed in holes in trees, or in puddles in walls, or in backyards. Detail one workman, and give him some cement and a trowel, and he will produce an economy of several pounds in the annual oilbill. The foreman must be charged not to leave a full oil-cart in the hot sun or it will become leaky, or even burst, and the oil will be wasted. Much money may be saved by attending to small items of this nature. In large open water collections oil may 
be economised by stocking them with fish or with the water-beetle Notonecta, " the water-boatman." Even when these exposed pools are oiled the wind may bank it up, and then the mosquito larvæ will thrive. Advise the municipality to fill up such places or to turn them into ornamental ponds, and put in some goldfish. But in this case see that the fish do not die; examine them periodically. Make a foreman responsible for this.

After the mosquitos have been reduced and the work is well maintained, it will become apparent that much labour would be saved if the cesspools were filled up and replaced by an efficient system of sewerage by water carriage; also that a great economy in water consumption would be effected, and water-tubs and cisterns dispensed with by a good filtered-water supply, if the pressure in the pipes could be made sufficient to reach the top stories of the highest houses in the town. If these could be installed, the cost of the mosquito campaign will fall considerably. But it is quite unreasonable to delay the institution of anti-mosquito measures until such major sanitary works have been installed, for the fever will continue.

In one or two towns mosquito measures have been said to have failed; for example, at Mian Mir, in India. This is because it was not properly or sincerely carried out. If the work is perseveringly done, it is bound to succeed. 


\section{CHAPTER XII}

RESULTS

AT the end of every year a full report may be published giving the results of the campaign and justifying the expenditure incurred. If the notebooks of the foremen or moustiquiers are examined, the number of water collections that harbour mosquito larvæ may be enumerated and compared with that obtained when the original estimate was made. The difference can be recorded. Then the fever census will give interesting results; but caution must be exercised, as already stated, in drawing conclusions. Usually some years must elapse before such deducttions are justified, although there is a marked reduction of the numbers of insects and the town is obviously healthier. Every effort must be made to obtain exact information. Regardless of the truth, natives have a happy way of expressing opinions that they think will please the questioner, and this fact must be remembered. Others also will sometimes cover the truth with a veneer of exaggeration if they think they will go up in the estimation of the Health Department or municipal councillor-it may 



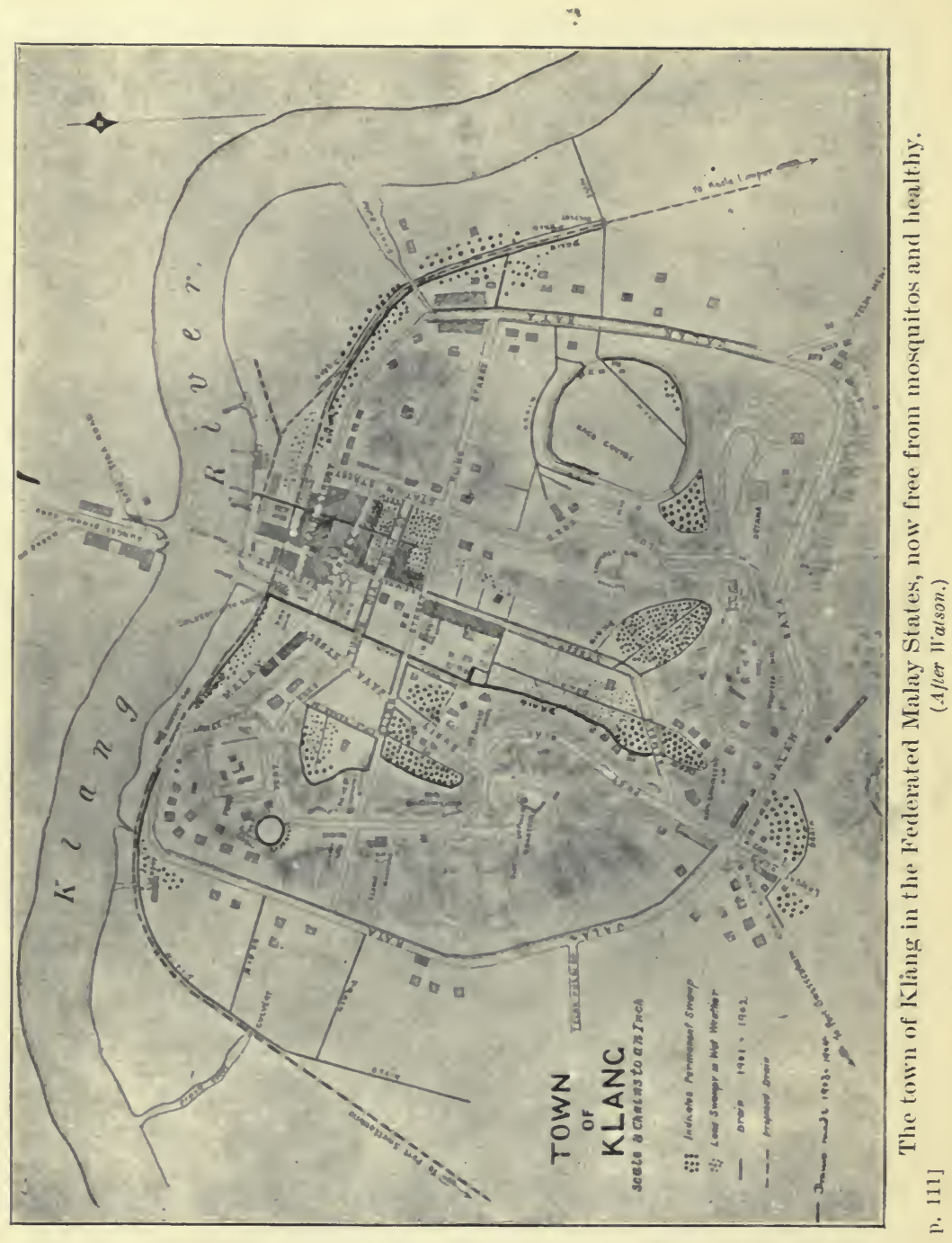


assist them sometime if they are "diplomatic." Care must always be exercised in accepting very favourable reports from such persons.

An attempt should be made at the end of each year to classify the fevers affecting the town. The doctors' returns should help in this. In most tropical towns there are many different kinds of fever which are most confusing. There are typhoid, Malta fever, malaria, simple continued fever, dengue, twelve-day fever, seven-day fever, and the phlebotomus, or threeday fever, recently differentiated. Then there is the possibility of latent yellow fever, the fever accompanying ankylostomiasis, endemic cirrhosis of the liver, sleeping sickness, kala azar, and a host of other affections as well as the zymotic diseases. It is not always easy to differentiate between these, and sometimes it is impossible.

It will require a great deal of painstaking research before all these diseases can be diagnosed from each other with certitude. But in the meantime efforts may be made to collect information from all sources about them. One good source is a carefully conducted mosquito campaign. The figures obtained from a frequent fever census taken before, during, and after the mosquito reduction will certainly be of the utmost use when attention is drawn to the anomalous fevers of warm climates, and researches upon them begun seriously. If fever statistics are drawn up carelessly, however, they will be useless for such a purpose.

The results should be published broadcast. The 
cause-mosquito reduction-is only in its infancy, and it is important that it should be instituted everywhere practicable. This can only be brought about by placing before the notice of the public its possibilities and the methods to be employed. This is the age of advertisement, and advertisement has become necessary if any new project is to succeed, or become generally known. Advertisement for such a cause is surely justifiable. Publish frequently, but let the publication be accurate-then others can learn from the experience gained.

It may be finally repeated that this work can be carried out not only by doctors alone, but by all persons who have the welfare of the community at heart. A scientific training is not absolutely essential for the accomplishment of mosquito reduction. Local Health Departments are the best organisers for anti-mosquito measures, but any really interested and responsible person in a town or village can do it if the lines laid down here are followed.

Lastly, it must be clearly understood that it is not possible to exterminate mosquitos in a given town, or even part of a town; it is only possible to reduce the numbers of gnats. Mosquitos are very local in their habits and do not fly far, as already emphasised -the fact is a most important one. At Port Said one part of the town was cleared first, while another remained untouched. The mosquito nets were largely dispensed with in the cleared district, but the insects continued as numerous as ever in the uncleared quarter; only one street separated the two portions. 
The same thing occurred in Cairo. Mosquito migration will not affect in any way the work of clearing towns, villages, or even parts of towns, of the insects. But if once cleared, and the work is allowed to fail for any reason, the mosquitos will surely return. At Ismailia and at Port Said, if the mosquito brigades stop work for a single week-even now after several years of continuous work-mosquitos return. This shows that it is not possible to exterminate mosquitos; they can only be reduced. But this reduction can be made so efficacious that the insects become reduced to a negligible quantity, and the fevers will be exterminated. Therefore it is clearly the duty of every one, wherever mosquitos exist, to start preventive measures against them, including those of the domestic species, in that extent of district as means will allow. Sooner or later the presence of mosquitos will mean the presence of disease carried by them, even if these do not exist already.

After the mosquitos have been reduced to negligible numbers, and the work is being well maintained at a diminished cost, the moustiquiers may be employed as ordinary sanitary inspectors. They will be well acquainted with the town, with all its houses, will know the inhabitants, who in turn will know them. They can then be utilised to report on insanitary places, unhealthy shops and overcrowded factories, dangerous trades, and can even notify disease or cases of sickness. They will learn from the servants which houses have sick tenants, and such cases can be investigated early and dealt with 
according to existing customs. After mosquito prevention has become an accomplished fact, a campaign against flies may be started in the same quarters. Flies breed in manure heaps, stables, cowsheds, improperly cleaned streets, ashbins, slaughter-houses, refuse depots, etc. The moustiquiers can be taught to deal with such places as part of their routine work. Fly reduction is almost as important as mosquito reduction. But the original object of the existence of the mosquito brigades should never be lost sight of. Should the unpopular mosquitos return, because the moustiquiers are being employed for other duties, their work will fall into disrepute, and they will become disheartened by complaints and grumblings. A mosquito campaign once started must always be continued with undiminished vigour. 



